\title{
A review of air filtration technologies for sustainable and healthy building ventilation
}

Article

Accepted Version

Creative Commons: Attribution-Noncommercial-No Derivative Works 4.0

Liu, G., Xiao, M., Zhang, X., Gal, C., Chen, X., Liu, L., Pan, S., Wu, J., Tang, L. and Clements-Croome, D. (2017) A review of air filtration technologies for sustainable and healthy building ventilation. Sustainable Cities and Society, 32. pp. 375-396. ISSN 2210-6707 doi: https://doi.org/10.1016/j.scs.2017.04.011 Available at https://centaur.reading.ac.uk/71549/

It is advisable to refer to the publisher's version if you intend to cite from the work. See Guidance on citing.

To link to this article DOI: http://dx.doi.org/10.1016/j.scs.2017.04.011

Publisher: Elsevier

All outputs in CentAUR are protected by Intellectual Property Rights law, including copyright law. Copyright and IPR is retained by the creators or other copyright holders. Terms and conditions for use of this material are defined in the End User Agreement.

www.reading.ac.uk/centaur 
Central Archive at the University of Reading

Reading's research outputs online 

filtration technologies for sustainable and healthy building ventilation. Sustainable Cities and Society, 32, 375-396.

\title{
A review of air filtration technologies for sustainable and healthy building ventilation
}

\author{
Guoliang Liu ${ }^{\mathrm{a}}$, Manxuan Xiao ${ }^{\mathrm{b}, 1}$, Xingxing Zhang ${ }^{\mathrm{c}, *}$, Csilla Gal $^{\mathrm{c}}$, Xiangjie Chen ${ }^{\mathrm{b}}$, Lin $\mathrm{Liu}^{\mathrm{d}}$, \\ Song Pan ${ }^{\mathrm{e}}$, Jinshun $\mathrm{Wu}^{\mathrm{e}}$, Llewellyn Tang ${ }^{\mathrm{b},{ }^{*}}$, Derek Clements-Croome ${ }^{\mathrm{f}}$ \\ a College of Texitile \& Clothing, Yancheng Institute of Technology, China \\ ${ }^{\mathrm{b}}$ Department of Architecture and Built Environment, University of Nottingham, Ningbo, China \\ ${ }^{c}$ Department of Energy, Forest and Built Environments, Dalarna University, Falun, 79118, Sweden \\ ${ }^{d}$ College of Urban Construction and Safety Engineering, Shanghai Institute of Technology, Shanghai, China \\ ${ }^{\mathrm{e}}$ College of Architecture and Civil Engineering, Beijing University of Technology, Beijing, China \\ ${ }^{\mathrm{f}}$ School of Construction Management and Engineering, University of Reading, Reading, UK \\ Corresponding authors: \\ E-mail addresses: xza@du.se (X. Zhang), Llewellyn.Tang@nottingham.edu.cn (L. Tang) \\ ${ }^{1}$ Joint First Authorship: The authors wish it to be known that, in our opinion, the first two authors should be regarded as joint First Authors.
}

Keywords:

Air filtration Standard

Synergistic effect Building Environment Ventilation

\section{A B S T R A C T}

Urbanization increased population density in cities and consequently leads to severe indoor air pollution. As a result of these trends, the issue of sustainable and healthy indoor environment has received increasing attention. Various air filtration techniques have been adopted to optimize indoor air quality. Air filtration technique can remove air pollutants and effectively alleviate the deterioration of indoor air quality. This paper presents a comprehensive review on the synergistic effect of different air purification technologies, air filtration theory, materials and standards. It evaluated different air filtration technologies by considering factors such as air quality improvement, filtering performance, energy and economic behaviour, thermal comfort and acoustic impact. Current research development of air filtration technologies along with their advantages, limitations and challenges are discussed. This paper aims to drive the future of air filtration technology research and development in achieving sustainable and healthy building ventilation.

\section{Introduction}

Salthammer (2004) reported that a large amount of household products, including furnishings and building materials, discharged VOCs (volatile organic compounds) during their lifetime. Materials for interior decorations are shown to be the sources of reactive compounds, which could lead to indoor air pollution. This problem becomes dominant when different materials react with each other (Singer et al., 2006). Some terpenoids and related compounds of many indoor air fresheners and cleaning products would volatilize during their usage period, which may form secondary pollutants when reacting with ozone (Liu, Mason, Krebs, \& Sparks, 2004; Nazaroff and Weschler, 2004; Sarwar, Olson, Corsi, \& Weschler, 2004; Wolkoff et al., 1998). Small changes of indoor air quality are often difficult to identify. Additionally, since people can only can perceive deteriorating air quality via sensory effects (such as odour annoyance, irritation of the airways and eyes) and central nervous system effect (such as headaches), adequate air filtering is of high importance (Gunnar, Lea, \& Peder, 1997).

Indoor air contaminants have been globally recognised as public health hazards during the last decade. The accumulation of contaminants leads to "sick building syndrome" (SBS) and to other reported diseases in affected spaces (Soreanu, Dixon, \& Darlington, 2013). While air filtration technology based building ventilation can remove air pollutants and increase indoor air quality, filters increase the systems' energy consumption and operating cost. The energy consumption is related to filter's resistance to air passing through it: the resistance increases when the filter is fouled and causes higher energy consumption. This can be a significant problem when air filtration is incorporated into the HVAC system. Additional problems such as acoustic impact and nonuniform thermal environment would occur by air filters. In order to achieve sustainable indoor environments, these problems need to be addressed. 
This paper presents a comprehensive review of the theory and materials of air filtration technology, standards related to air filtration in building ventilation and the synergistic effect of different air purification technologies. General research development is then discussed through air quality improvement, performance and energy assessment, thermal comfort and acoustic impact, etc. This paper aims to provide guidance to future research and development in air filtration technology for achieving sustainable and healthy building ventilation.

\section{Air filtration technology for healthy and sustainable built environment}

Occupants' comfort and health can be adversely affected by poor indoor air quality. According to the latest report of Amos (2016), more than 5.5 million people worldwide dies prematurely every year due to outdoor and indoor air pollution. For instance, breathing in tiny liquid or solid particles increases the risk of respiratory complaints, stroke, heart disease and even cancer. The Global Burden of Disease project puts air pollution as the fourth greatest risk after high blood pressure, dietary risks and smoking. However, it might not be easy to achieve high level indoor air quality, as there are many sources of indoor pollution, such as building materials, finishes and furnishings, which all can release toxic fumes. Furthermore, special emphasis placed on building "airtightness" by the building construction industry in order to improve the energy efficiency of buildings. This makes it more difficult to obtain better indoor air quality through natural ventilation. As a consequence, the air-tight buildings likely compromise the health of occupants, while successfully conserving energy (Lee, Biasio, \& Santini, 1996). Nevertheless, energy efficiency remains to be a central issue due to our limited resources. Thus, building energy conserving strategies must also incorporate strategies for protecting and improving occupant health.

Ventilation plays a crucial role in maintaining a clean indoor environment. However, ventilation systems can also be major sources of airborne pollutants as a result of inadequate system design, distribution, cross contamination, etc. Thus, air filtration technology plays a key role in protecting human health by removing indoor air pollutions, while also providing an alternative solution for reducing energy usage, operating costs and thus delivering a way to achieve sustainability.

\section{Theory of air filtration technology}

\subsection{Classic filtration theory}

Filtration theory was developed from the early classical filtration theory in 19th century, to the modern filtration theory and microporous filter theory (as summarized in Table 1). Fine particle movement was first observed by botanist Brown in the early 19th century when fine particulates suspending in the liquid, which was defined as Brownian motion (Thomas, Penicot, Contal, Leclerc, \& Vendel, 2001). In 1922, Freundlich presented understanding of the law on aerosol filtration and indicated aerosol particles' maximum permeability existed within a radius of $0.1 \mu \mathrm{m}$ to $0.2 \mu \mathrm{m}$ (Rosner, Tandon, \& Konstanpulous, 1995). In 1931, Albrecht took the lead to research air movement through a single cylindrical fibre and established the Albrecht theory, which Sell later improved (Kvetoslav, 1998).

In 1936, Kaufmann was the first to apply the Brownian motion and inertia settling to fibre filtration theory and deduced the mathematical formula of the filtering effect. By 1942, Langmuir recognized filtering is mainly affected by interception and diffusion, while the deposition of the inertial particles on the filter fibre could be ignored (Davies, 1973). Davies (1952) combined diffusion, interception and inertia mechanisms, formula express and built a new filtering theory: the isolated fibre theory. Friedlander (1958) and Yoshioka (in 1967) developed the above isolated fibre theory separately. They researched and concluded filter blocking phenomenon as well as the effect of inertia, deposition and gravity (Friedlander, 1958, Rosner et al., 1995, Thomas et al., 2001). 
In 1967, Pickaar and Clarenburg proposed a mathematical theory for fibre filter microporous structure (Wang, 2001). Payet, Boulaud, Madelaine and Renoux (1992) considered the introduction of classical theory's correction factors could make the theory fit better with the experimental data when the gas sliding over a single fibre. Rosner et al. (1995) improved the theory and proposed the spatial distribution of particles in a single fibre, as particle dispersed on the surface of a single fibre was irregular and often characterized by the formation of dendritic structure. The theory and computational procedure can be used to predict the particle deposition. Thomas et al. (2001) theoretical and experimental researched air filters under blocking condition and put forward filter efficiency and pressure loss calculation model of the air filter with the circumstance of filter cake. In recent years, many researchers have conducted theoretical simulations and experiments on the formation and mechanism of filter cake with some achievements.

Conventional filtering materials' filtration mechanism (as indicated in Fig. 1) is the result of various kinds of synthesized effects, such as the inertial effect, the diffusion effect, the interception effect, the electrostatic effect, gravity, the thermophoresis effect and the Van der Waals force, etc., of which the first three are the predominantly govern filtration mechanisms.

The inertia capture mechanism is closely related to the mass of the particles. The inertia effect occurs when particles move with airflow. Particulate matters that are not within the airflow streamline will be arrested by the fibre surface when the flow changes. The inertial capture efficiency is greatly influenced by wind speed, as it is the function of Stokes parameter $(S t)$ and Reynolds number $(R e f)$. The bigger the particle size, the greater the inertia and the higher the inertia efficiency will be.

Diffusion capture mechanism occurs when small size particles are captured by the fibre surface with gas molecule collisions and random movement. Diffusion captures mechanism is a function of Reynolds number $(\operatorname{Re})$ and the Peclet number $(\mathrm{Pe})$. This mechanism is most significant for particles less than $1 \mu \mathrm{m}$. The smaller the particle size, the more intense the random movement and the more obvious the diffusion efficiency is. Research shows that the theoretical calculation value of the diffusion capture efficiency becomes greater than $80 \%$ when the particle size is less than 0.1 $\mu \mathrm{m}$. Under these circumstances, other capture efficiency can be ignored.

Interception capture mechanism occurs when particles move with airflow, as the distance between the streamline of the particle's centreline and the streamline of the fibre centreline is less than or equal to the sum of fibre radius and particle radius. Interception efficiency is affected by Reynolds number and intercept coefficient (Colbeck and Lazaridis, 2013).

Table 1

Development process of filtration theory.

\begin{tabular}{|c|c|c|}
\hline Time & Researcher & Achievement \\
\hline $\begin{array}{l}\text { Beginning of } 19 \text { th } \\
\text { century }\end{array}$ & Rebert Brown & Brownian movement \\
\hline 1922 & Freundlich & penetrating particle size of particles range: $0.1-0.2 \mu \mathrm{m}$ \\
\hline 1931 & Sell & improved Albrecht theory \\
\hline 1936 & Kaufmann & First derived the fibre filtering formula considering the diffusion and the inertia effect \\
\hline 1942 & Langmuir & filtration theory of interception and diffusion and ignored the inertial deposition \\
\hline 1952 & C.N. Davies & Isolated fibre theory \\
\hline 1958 & Friedlander & Summarized the inertia and diffusion deposition with bigger Reynolds number \\
\hline 1967 & Yoshioka and others & \\
\hline 1967 & Pickaar,Clarenburg & A mathematical theory of fibre filter microporous structure \\
\hline 1992 & Payet, Boulaud, Madelaine \& Renoux & Considered the gas sliding over a single fibre, correction factor introduced to the classical theory \\
\hline 1995 & Rosner et al. & $\begin{array}{l}\text { Particle dispersed on the surface of a single fibre was of irregular distribution and of dendritic structure, and } \\
\text { predict particles deposition by this theory and calculation procedure }\end{array}$ \\
\hline 2001 & Thomas et al. & $\begin{array}{l}\text { Theoretical and experimental researched air filters under blocking condition and put forward filter efficiency } \\
\text { and pressure loss calculation model of the air filter with the circumstance of filter cake. }\end{array}$ \\
\hline
\end{tabular}


Table 2

Filtration mechanisms of different electret filtration processes.

\begin{tabular}{|c|c|c|c|c|}
\hline Particle & Fibre & $\begin{array}{l}\text { Electric } \\
\text { field }\end{array}$ & $\begin{array}{l}\text { Electrostatic } \\
\text { force }\end{array}$ & Expression \\
\hline Charged & Charged & None & $\begin{array}{l}\text { Coulomb } \\
\text { force }\end{array}$ & $N_{E}=\frac{q Q}{2 \pi e_{0} r}$ \\
\hline Charged & Uncharged & None & Image force & $N_{E}=\frac{1}{16 \pi x_{0}}\left(\frac{e_{f}-1}{e_{f}+1}\right) \frac{q^{2}}{\left(r-r_{f}\right)^{2}}$ \\
\hline Uncharged & Charged & None & $\begin{array}{l}\text { Induction } \\
\text { force }\end{array}$ & $N_{E}=\frac{d_{p}^{3}}{8 \pi e_{0}}\left(\frac{e_{p}-1}{\varepsilon_{p}+2}\right) \frac{Q^{2}}{r^{2}}$ \\
\hline Uncharged & - & $\begin{array}{l}\text { External } \\
\text { electric } \\
\text { field }\end{array}$ & $\begin{array}{l}\text { Polarization } \\
\text { force }\end{array}$ & $N_{E}=\frac{\pi \varepsilon_{0} d_{p}^{3}}{4}\left(\frac{e_{p}-1}{e_{p}+2}\right) \nabla|E|^{2}$ \\
\hline Charged & - & $\begin{array}{l}\text { External } \\
\text { electric } \\
\text { field }\end{array}$ & Image force & $N_{E}=q E$ \\
\hline
\end{tabular}

\footnotetext{
$\varepsilon_{0}=$ permittivity of free space; $\varepsilon_{p}=$ dielectric constant of particle; $\varepsilon_{\mathrm{f}}=$ dielectric constant of fibre; $d_{p}=$ particle diameter; $d_{f}=$ fibre diameter; $r_{f}=$ fibre radius; $q=$ net charge on particle; $Q=$ net charge on unit length of fibre; $E_{0}=$ sexternally applied electric field; $\sigma=$ surface charge density; $r=$ radial distance from fibre axis; $\theta=$ polar angular coordinate; $E=$ electric field with components.
}

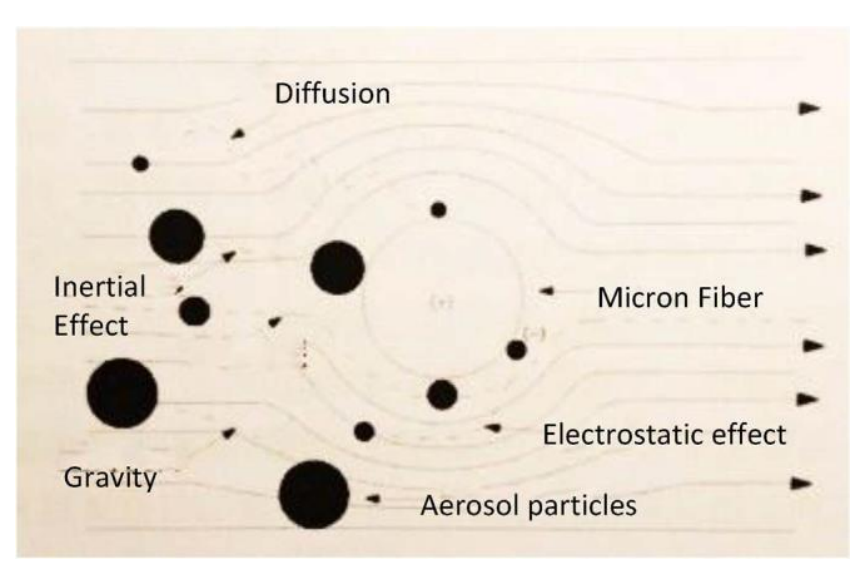

Fig. 1. Schematic diagram of single fibre capture mechanisms.

\subsection{Electrostatic capture mechanisms}

Electrostatic capture efficiency refers to the collection efficiency of particles or fibres in the electric field formed by opposite charged Coulomb force, image force and polarization force of electric field emission. Table 2 lists the mechanism of electrostatic filtration for particulate matters and fibres in different conditions (Wang, 2001).

$$
E_{r}=\left[1+\left(\frac{\varepsilon_{f}-1}{\varepsilon_{f}+1}\right) \frac{r_{f}^{2}}{r^{2}}\right] E_{0} \cos \theta, E_{\theta}=\left[1+\left(\frac{\varepsilon_{f}-1}{\varepsilon_{f}+1}\right) \frac{r_{f}^{2}}{r^{2}}\right] E_{0} \sin \theta
$$

\subsection{Filtration characteristics of air filtration materials}

Several studies examined the factors affecting the purification characteristics of air filtration materials. Myers and Arnold (2003) researched the filtration performance characteristics of electrically charged continuous filament meltspun (CFM) media, which provided a combination of static charge and structure. Field tests had been conducted on both electrically charged and non-charged CFM media structures and illustrated their potential mechanical filtration properties. Research results showed that the key of electret HVAC media's performance characteristics was the synergistic relationship between the charge distribution and web structure. Additionally, field studies indicated that both charged and non-charged CFM media provide better initial and long-term filtration efficiency than cotton/polyester media of equivalent basis weight. Similarly, Das and Waychal's work (2016) characterized the triboelectrically charged nonwoven electrets, which adopted needle-punched nonwoven technology and employed 
wool and polypropylene fibres. They found that the filtration efficiency of this electret media was remarkably higher than that of uncharged media and hence was proved to be an excellent fibre filtration material. The magnitude and duration of electrical charge decreased with the increase of fibre diameter.

Shenghsiu et al. (2013) examined the major parameters of electret filter media-such as fibre diameter, filter thickness, packing density, fibre charge density and face velocity - through both theoretical models and experimental methods. The study found that fibre charge density and face velocity are more significant for filtration efficiency than other factors, and that filtering efficiency increases with increasing fibre charge density and with decreasing face velocity. Moreover, decreasing fibre charge density, filter thickness and packing density, increases aerosol penetration through the electret filter media. In contrast, aerosol penetration is in direct proportion to fibre diameter and face velocity. The study of Wang, Kim, and Pui (2008) focusing on air filters with nanofibre layer and micrometre fibre base, established the mathematical model for numerical simulation studies and compared the performance of these filters with traditional fibre ones.

For a long time, studies in air filtration theory focused on the collection efficiency and pressure drop of clean filter materials at a stable phase. However, these studies are of a limited significance for high efficiency and ultra-low particulate air filters. There are only a handful of studies addressing the long-time unsteady filtering process, which leads to increased operating costs and is also critical for service life. Unsteady filtering theory emphasizes the role of air filters in ventilation and air conditioning systems.

Based on an existing model, Payet et al. (1992) put forward the empirical formula of purification efficiency that is suitable for deep filtering and for transition-zone surface filtering. Using fluorescein sodium aerosol and scanning electron microscopy (SEM) Thomas et al. (2001) evaluated the relationship between fibre filter purification efficiency and obtained dust quantity, and found different dust structures at different thickness of the filter material. Utilizing the Channel Theory and the Drag Theory, Endo, Chen, and Pui (2002) studied the fluid resistance of the dust filling layer theoretically. They proposed improvements to the equations that consider the effects of particle dispersion and particle shape on resistance. Fu, Kang, and Shen (2010) established a mathematical model of dust concentration distribution inside the fibre filter on the basis of the law of quality conservation. They proposed two assumed conditions: one condition was single fibre with dust load and varying collection efficiency, the other was single fibre with dust load and invariable collection efficiency. Thus, two collection efficiency formulas were obtained and calculation results were compared with related experiments. The study demonstrated that the results of the mathematical model under the two conditions were almost same. Related experiments confirmed the findings of the theoretical study. The logarithm interpenetration law was a special case of the model and two formulas of collection efficiency were applicable for both non-stationary filtration and stationary filtration.

The unsteady electrostatic dust filtration efficiency of a single fibre can be expressed as the logarithmic function of dust weight on the fibre surface in unit volume (Sae-Lim, Tanthapanichakoon, \& Kanaoka, 2004) and the unsteady mechanical filtration efficiency can be expressed as the linear function of dust weight on the fibre surface in unit volume (Kanaoka, Emi, \& Tanthapanichakoon, 1983). Kanaoka, Emi, and Myojo (1980) put forward a kind of conventional fibre three- dimensional stochastic model to predict deposition on a conventional fibre surface due to convection and Brown diffusion. They found a linear relationship between the ratio of the efficiency of single fibre and clean material or dust capacity. Baumgartner and Loffler (1986) experimentally compared the characteristics of different types of electret filter materials with or without dust, and predicted the clean filter material filtration efficiency by simulating the deposition on a fibre surface of a cylindrical electret filter material fibre. Brown, Gray, Blackford, and Bostock (1988) found that the filtration efficiency of electret filtration materials decreased exponentially with time as a result of the electrostatic decay. Walsh and Stenhouse (1997) studied the unsteady filtering characteristics of electret filter materials under different particle size, charging status and composition They found that during unsteady filtering, the lowest efficiency point and the blocking point appeared faster for smaller scale particles and for larger scale particles, respectively. Similarly, Ji, Bae, Kang, and Hwang (2003) found that filter characteristics of the electret filtering process are affected by the quantity, scale, and elements of particulate matters. In addition, the filtration efficiency of electret material decreased with increasing dust capacity and the minimum occurred at the stable stage. Tanthapanichakoon, Maneeintr, Charinpanitkul, and Kanaoka (2003) presented a three dimensional stochastic model to simulate the deposition process on electret fibre's surface considering diffusion effect, which can predict the coagulation deposition process. At weak electrostatic effect, the relationship between the enhancement factor of electret filtration efficiency and the dust quantity is linear. 


\section{Air filtration materials}

\subsection{Classification of air filtration materials}

Glass fibre air filter material appeared in the United States and obtained US patent in 1940. Since then, it developed rapidly. By the 1970s, the HEPA (high efficiency particle air filter) with super fine glass fibre paper could achieve $99.9998 \%$ efficiency for $\geqq 0.3 \mu \mathrm{m}$ dust (Liu and Wang, 2000). Since the 1950s, the global manufacturing industry developed rapidly and opened a new chapter in air filter materials.Activated carbon fibre (ACF) started to be developed by Japanese in 1970 with rayon, polypropylene nitrile, etc., as raw materials. ACF isconsidered to be one of the best air purification materials in $21^{\text {st }}$ century due to its advantages of rich form, more effective absorption pore, uniform pore size distribution, short adsorption trip, high stripping speed, large adsorptive capacity and easy regeneration (Bandosz and Ania, 2006). Nanotechnology was born in the late 1980s. The main form of nanomaterials in the air filtration field is nanofibre. Nanometre fibre has a larger specific surface area, surface energy and surface tension, which increase the deposition of airborne particulates on fibre surface and consequently improve filtration efficiency. Under the same pressure loss, both the direct interception and the inertial impact effect of nanofibre are more significantly than which of traditional plant fibre, this leads to resistance reduction, increased filtration efficiency and longer service life (Wang, Yang, Liu, Zheng, \& Liu, 2016).

In early 1990s, US Company Lydair produced a ULPA filter (Ultra Low Penetration Air Filter) with super fine glass fibre, which could achieve $99.999999 \%$ efficiency for $0.1 \mu \mathrm{m}$ dust. It greatly contributed to the development of electronic, aerospace, precision machinery and other industries with high requirement of indoor air quality. Glass fibre has become a traditional filtering material used in a variety of filtration equipment, such as breathing apparatus, household dust filter, air filter and HVAC system (heating, ventilation and air conditioning) (Tsai and Ke, 2003). Film compound filter material was developed by the mid- 1990s. It was made from polytetrafluoroethylene covered in fabric, nonwoven cloth or glass fibre filter material. It gradually became more popular in dust purification and air conditioning industries due to its advantages of high filtration efficiency (above $99.9 \%$ for submicron dust), low resistance $(30 \%-40 \%$ lower than traditional filter material), long service life (up to 2-5 times of the traditional filter material), high temperature resistant (up to $280{ }^{\circ} \mathrm{C}$ ) and high dust peeling rate (Huang, Mao, Mei, \& Huang, 2001).

Nano-titanium dioxide ( $\mathrm{TiO} 2)$ photocatalytic material is the most promising filtration material of the 21st century to eliminate harmful gases. Ultraviolet (UV) excitation energy would occur after materials absorbed UV rays hence leads to oxidation-reduction reaction, which formed superoxide anionic radicals and strong oxidizing hydroxyl radicals that can effectively degrade $\mathrm{NOx}, \mathrm{CO}, \mathrm{NH} 3, \mathrm{SO} 2$, and $\mathrm{VOC}$ etc. gases to $\mathrm{H} 2 \mathrm{O}, \mathrm{CO} 2$ and other corresponding inorganic elements. This reaction occurs under ambient pressure and temperature, purifies the air and achieves sterilization without secondary pollution. Inaddition, further indoor air purification can be achieved as it combines different composite materials (Zhang, Zhao, Wu, \& Fang, 2015). According to Jasper et al. (2006), electret filter material has attracted more public attention due to its lower pressure drop and betterfiltration performance in conditions when traditional filter medias exhibit low filtering efficiency or high resistance. Electret filtration material uses the electrostatic effect between the particles and filtering fibres to enhance the dust filtration efficiency. The efficiency can be improved without resistance increase, because the electrostatic effect not only makes fibre extension, but also makes deposited dust present chain or dendritic structure. The application of electret filter media is growing rapidly in various fields and gradually replacing glass fibre filtration material. The application of air filtration material has gradually developed from a variety of industrial fields to indoor air quality improvement. Targeted and functional air filtration materials could be future directions in air filter media development.

\subsection{Classification of air filtration materials}

According to the filtration efficiency of PM10, PM2.5 and PM1.0, Table 3 classifies and summarizes general air filter materials along with their filtration characteristics. According to Section 4.1, in most circumstance, glass fibre and activated carbon fibre can be used as primary or mid-efficiency filter materials, while the high-efficiency filter materials are the super fine glass fibre, Nanometre fibre, film compound filter material and electret filter material. 
Table 3 Classification of air filter material.

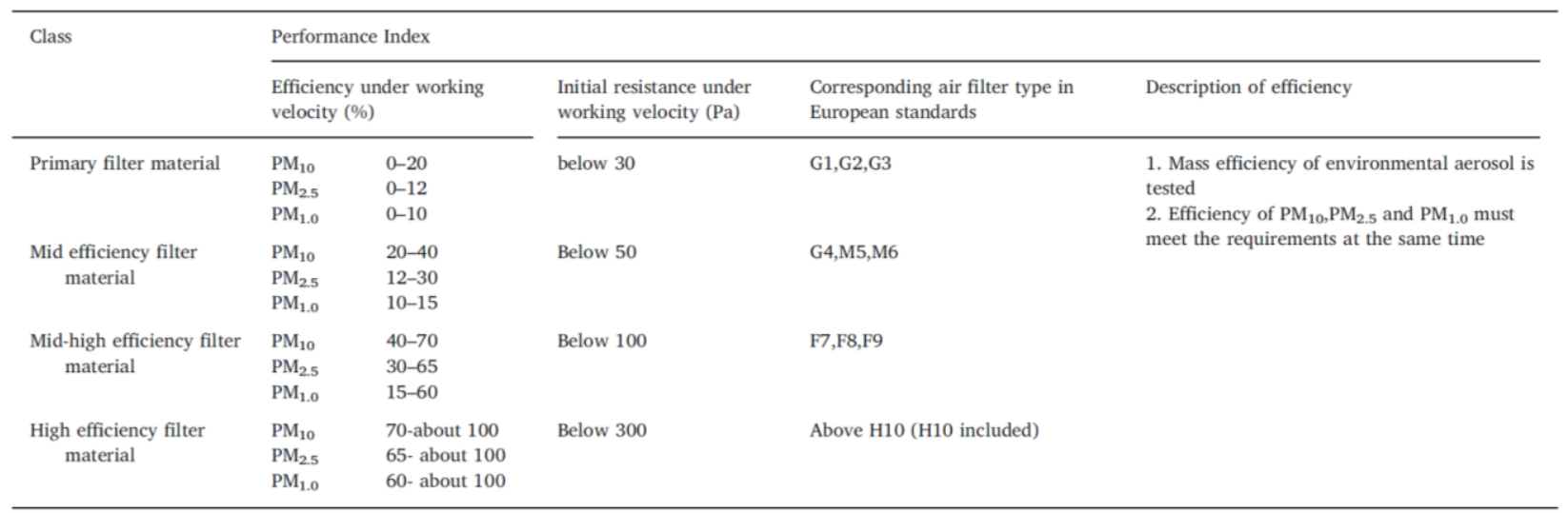

\section{Standards or regulations related to air filtration in building}

\subsection{Air quality standards}

Section 5.1 provides a systematically analysis of worldwide ambient and indoor air quality standards. Although these standards cannot be directly used, they can be regarded as examples for countries that need to establish corresponding ambient and indoor PM2.5 pollution regulations. These countries can take advantage of the known technical route, research framework and concentration limits.

\subsubsection{Ambient air quality standards}

Table 4 lists the standard limit of PM2.5 concentrations of different countries and organizations (Australian Government, 2003; European Commission, 2010; Japanese Government, 2009; MEPC, 2012; United States Environmental Protection Agency, 2006; WHO, 2006). America was the first to formulate National Ambient Air Quality Standards (NAAQS) and made detailed implementation plan since 1997. Except for the daily and annual PM2.5 concentration limits, the World Health Organization (WHO) set up three transition targets for countries or regions that cannot reach the goal at the present stage. According to the WHO standards of periodic value of PM2.5, Australia has already reached the WHO guidelines followed by the USA and Japan meeting the Interim target-3, with EU achieving the Interim target-2. Japan has the most restrictive PM2.5 emission standards in Asia, while China is still working at the Interim target-1. Though Chinese PM2. 5 standard GB 3095-2012 is currently implemented in stages, there is still a long way to go for Chinese environmental air pollution control.

Table 4 Global concentration limits for outdoor PM2.5.

\begin{tabular}{llll}
\hline Issued by & $\begin{array}{l}\text { Annual Mean } \\
\left(\mu \mathrm{g} / \mathrm{m}^{3}\right)\end{array}$ & $\begin{array}{l}24-\mathrm{h} \text { Mean }(\mu \mathrm{g} / \\
\left.\mathrm{m}^{3}\right)\end{array}$ & Time \\
\hline $\begin{array}{l}\text { WHO guidelines } \\
\text { WHO Interim target-1 }\end{array}$ & 10 & 25 & 2005 Notification \\
WHO Interim target & 25 & 75 & \\
$\quad-2$ & & 50 & \\
WHO Interim target & 15 & 37.5 & \\
$\quad-3$ & & & 2003 Notification \\
Australia & 8 & 25 & 2006 Effective \\
USA & 15 & 35 & 2009 Notification \\
Japan & 15 & 35 & 2010 Notification \\
EU & 25 & - & 2012 Notification \\
China & 40 & 75 & \\
\hline
\end{tabular}




\subsubsection{Indoor air quality standards}

Table 5 lists the indoor environment control standards of particulate matters (PM). The indoor PM standards issued by USA NAAQS/EPA, USA OSHA Industry and German Occupational Health Association focus on industrial environments. Hongkong Indoor Air Quality standard concentrates on office buildings and public places whereas Mainland China Indoor Air Quality standard aims at residential and office buildings. Currently, only few countries have established PM2.5 control standards and recommended limits for indoor environments. China, Australia and New Zealand only regulate indoor PM10 concentration levels, while the United States and the European Union have also prescribed concentration limit for PM2.5. The Chinese standard limits indoor PM10 at $150 \mu \mathrm{g} / \mathrm{m} 3$, New Zealand's at $120 \mu \mathrm{g} / \mathrm{m} 3$, while Australia and the EU set it at $100 \mu \mathrm{g} / \mathrm{m} 3$. Compared to outdoor PM2.5 control standards, indoor PM2.5 control standards still need to be optimized.

Table 5 Global concentration limits for indoor PM.

\begin{tabular}{|c|c|c|c|c|}
\hline \multirow[t]{3}{*}{ Issued by } & \multicolumn{4}{|l|}{ Pollutants } \\
\hline & \multicolumn{2}{|l|}{$\mathrm{PM}_{2.5}\left(\mu \mathrm{g} / \mathrm{m}^{3}\right)$} & \multicolumn{2}{|c|}{$\mathrm{PM}_{10}\left(\mu \mathrm{g} / \mathrm{m}^{3}\right)$} \\
\hline & Annual Average & $\begin{array}{l}\text { Daily } \\
\text { Average }\end{array}$ & $\begin{array}{l}\text { Annual } \\
\text { Average }\end{array}$ & $\begin{array}{l}\text { Daily } \\
\text { Average }\end{array}$ \\
\hline $\begin{array}{l}\text { USA NAAQS/EPA } \\
\text { (2000) }\end{array}$ & 15 & 65 & 50 & 150 \\
\hline USA OSHA Industry & 5000 & & - & \\
\hline $\begin{array}{l}\text { German Occupational } \\
\text { Health Association } \\
(2000)\end{array}$ & $1500(<4 \mu \mathrm{m})$ & & 4000 & \\
\hline Canada (1995) & $100[1 \mathrm{~h}]$ & $40[8 \mathrm{~h}]$ & - & \\
\hline EU WHO (2000) & 10 & 25 & 20 & 50 \\
\hline $\begin{array}{l}\text { Hongkong Indoor Air } \\
\text { Quality (2003) }\end{array}$ & - & & $18-20$ & \\
\hline $\begin{array}{l}\text { Mainland China Indoor } \\
\text { Air Quality (2002) }\end{array}$ & - & & - & 150 \\
\hline $\begin{array}{l}\text { Australian Ambient Air } \\
\text { (1998) }\end{array}$ & - & & - & 50 \\
\hline $\begin{array}{l}\text { New Zealand Ambient } \\
\text { Air Quality (2000) }\end{array}$ & - & & 40 & 120 \\
\hline
\end{tabular}

\subsection{Air filter standards}

Air filters' test methods are developing with the progress of relevant monitoring technology. In 1938 the USA was the first to develop the National standard of colorimetric efficiency test method for air filters. Then Germany, UK, France and other European countries followed with their filter testing methods during the fifties and sixties. Finally, European Ventilation Association issued the EUROVENT 4/5 standards on the basis of ASHRAE52-76 standard in 1979. In the latest European standard EN 779:2011, the original F5 and F6 classification was changed to M5 and M6 grades respectively, and for class F7 to F9 air filters the lowest efficiency was set to $0.4 \mu \mathrm{m}$. Table 6 presents the air filter classifications according to the EN 779: 2012 standard (Comité Européen De Normalisation, 2012).

In the early 1980s, Chinese researchers proposed atmospheric dust counting method for air filters' detection and classification, which served as the basis of the Chinese national air filter test standard GB12218-89. In 1993, GB/T14295-93 was proposed utilizing the same detection method of GB12218-89, which was revised in October 2005. The latest standard GB/T14295-2008 (presented in Table 7) is in effect since January 2008 and revised since January 2016. 
Table 6

Air filter classification according to EN779:2012 (Adapted from Comité Européen De Normalisation (2012)).

\begin{tabular}{llllll}
\hline Category & $\begin{array}{l}\text { Filter } \\
\text { Class }\end{array}$ & $\begin{array}{l}\text { Final } \\
\text { pressure } \\
\text { drop }(\mathrm{Pa})\end{array}$ & $\begin{array}{l}\text { Average } \\
\text { arrestance }\left(A_{m}\right) \\
\text { of synthetic dust } \\
(\%)\end{array}$ & $\begin{array}{l}\text { Average } \\
\text { efficiency }\left(E_{m}\right) \\
\text { of } 0.4 \mu \mathrm{m} \\
\text { particles }(\%)\end{array}$ & $\begin{array}{l}\text { Minimum } \\
\text { Efficiency } \\
\text { for } 0,4 \mu \mathrm{m} \\
\text { particles } \\
(\%)\end{array}$ \\
\hline \multirow{2}{*}{ Coarse } & G1 & 250 & $50 \leq A_{m}<65$ & - & - \\
& G2 & 250 & $65 \leq A_{m}<80$ & - & - \\
& G3 & 250 & $80 \leq A_{m}<90$ & - & - \\
& G4 & 250 & $90 \leq A_{m}$ & - & - \\
Medium & M5 & 450 & - & $40 \leq E_{m}<60$ & - \\
& F6 & 450 & - & $60 \leq E_{m}<80$ & - \\
& F7 & 450 & - & $80 \leq E_{m}<90$ & 35 \\
& F8 & 450 & - & $90 \leq E_{m}<95$ & 55 \\
& F9 & 450 & - & $95 \leq E_{m}$ & 70 \\
\hline
\end{tabular}




\begin{tabular}{|c|c|c|c|c|c|c|}
\hline \multirow[t]{2}{*}{ Category } & & \multicolumn{2}{|c|}{ Rated wind speed (m/s) } & \multicolumn{2}{|l|}{ Purification efficiency (\%) } & \multirow[t]{2}{*}{ Initial pressure drop (\%) } \\
\hline & & Air filter & Filter media & & & \\
\hline Sub high & YG & 1.0 & 0.053 & Diameter $\geq 0.5 \mu \mathrm{m}$ & $99.9>E \geq 95$ & $\leq 120$ \\
\hline High medium & GZ & 1.5 & 0.100 & & $95>\mathrm{E} \geq 70$ & $\leq 100$ \\
\hline Medium 1 & $\mathrm{Z} 1$ & 3.0 & 0.200 & & $70>E \geq 60$ & $\leq 80$ \\
\hline Medium 2 & $\mathrm{Z} 2$ & & & & $60>E \geq 40$ & \\
\hline Medium 3 & $\mathrm{Z3}$ & & & & $40>\mathrm{E} \geq 20$ & \\
\hline Coarse 1 & $\mathrm{C} 1$ & 2.5 & 1.000 & Diameter $\geq 2.0 \mu \mathrm{m}$ & $E \geq 50$ & $\leq 50$ \\
\hline Coarse 2 & $\mathrm{C} 2$ & & & Standard artificial dust weight efficiency & $50>\mathrm{E} \geq 20$ & \\
\hline Coarse 3 & $\mathrm{C} 3$ & & & & $\mathrm{E} \geq 50$ & \\
\hline Coarse 4 & $\mathrm{C} 4$ & & & & $\mathrm{E} \geq 50$ & \\
\hline
\end{tabular}

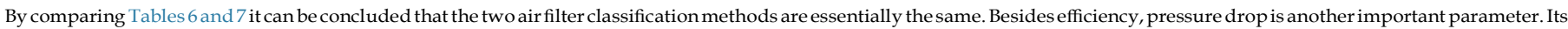
importance is discussed in Section 7.3.

\section{Synergistic effect from integration with other air purification technologies}

\subsection{The effect of single purification technique on main pollutant types}

The main pollutants in the air can be divided into three categories: suspended particles, volatile organic pollutants and microorganisms. Table 8 lists the effect of individual purification techniques on the main types of pollutants (Zhang, Mo et al., 2011). In terms of suspended particles, the main purification technologies are filtration, water washing purification, electrostatic precipitation and anion technology. Filtration is currently the most widely used purification technique of particulate matters. The most effective and commonly used purification method for harmful gases is adsorption. Because of its simplicity, effectiveness and low cost, activated carbon is a widely used adsorption material. In addition, photocatalytic and plasma cleaning technologies are also effective for the purification of volatile organic pollutants. For the elimination of microorganisms, the most efficient method is UV light, followed by photocatalytic and plasma purification. Filters are more effective in the case of bacteria with larger diameter, while they are not suitable for eliminating virus.

Based on the characteristics of different purification technologies, it can be concluded that a purification technique cannot succeed in an environment characterised by the multiplicity of air pollutants. In order to purify the air to the fullest, it is necessary to combine various purification methods corresponding to the types of pollutants present in the air. Complementary advantages of different purification technologies exalt each other, but combining various purification methods might also expose and bolster the included methods' disadvantages. Therefore, when adopting multiple technologies, their characteristics should be carefully analysed in order to obtain the most suitable outcome.

Most indoor air pollution purification technologies originate from industrial exhaust gas and related gas treatment technologies. They can be mainly classified into three categories: dust removal technology, gas purification and sterilization technology. Prevailing indoor air dust removal technologies are derived from atmospheric dust removal technologies. The most commonly applied methods are fibre filtration and electrostatic dust removal. In terms of gas purification, activated carbon filtration is still the most prevalent approach. Ozone (O3) and ultraviolet (UV) radiation are still the most frequently adopted sterilization technologies. The characteristics of commonly used purification technologies are shown in Table 9.

Table 8 Effect of single purification technology to main types of pollutants.

\begin{tabular}{|c|c|c|c|c|}
\hline \multirow[t]{4}{*}{ Purification Technique } & \multicolumn{4}{|l|}{ Pollutants } \\
\hline & \multirow{3}{*}{$\begin{array}{l}\text { Suspended particles } \\
\text { Dust, pollen, secondary pollutants, lampblack, } \\
\text { etc. } \\
\text { Diameter } 0.01-100 \mu \mathrm{m}\end{array}$} & \multirow{3}{*}{$\begin{array}{l}\text { Volatility organic contaminants } \\
\text { Formaldehyde, benzene, ammonia, etc. } \\
\text { Diameter } 0.0001-0.001 \mu \mathrm{m}\end{array}$} & \multicolumn{2}{|l|}{ Microorganism } \\
\hline & & & Bacteria & Virus \\
\hline & & & Diameter $0.2-10 \mu \mathrm{m}$ & Diameter $0.01-0.3 \mu \mathrm{m}$ \\
\hline Filtration & Effective & Noneffective & Effective & Noneffective \\
\hline Adsorption & Partially effective & High-efficiency & Partially effective & Noneffective \\
\hline Water washing purification & Effective & Partially effective & Noneffective & Noneffective \\
\hline Electrostatic precipitation & Effective & Not obvious & Partially effective & Noneffective \\
\hline Anion technology & Effective & Not obvious & Partially effective & Noneffective \\
\hline Photocatalysis purifying technology & Not obvious & Effective & Effective & Effective \\
\hline Plasma cleaning technology & Not obvious & Effective & Effective & Effective \\
\hline Ultraviolet radiation & Noneffective & Noneffective & High-efficiency & High-efficiency \\
\hline
\end{tabular}




\begin{tabular}{|c|c|c|c|c|}
\hline Technologies & Target & Advantages & Disadvantages & Efficiency \\
\hline Fibre filtration & Particles, microorganism, Rn & Low cost, convenient installation & $\begin{array}{l}\text { Resistance related to the purification efficiency, mid and high efficiency } \\
\text { filters of high resistance }\end{array}$ & Can achieve $99.99999 \%$ \\
\hline dectrostatic dust removal & Particles microorganism & $\begin{array}{l}\text { High efficiency and wild range of particle size, small } \\
\text { pressure loss }\end{array}$ & $\begin{array}{l}\text { High investment, efficiency decline after dust discharge, electric field easy } \\
\text { to breakdown }\end{array}$ & $50 \%$ (some only 20\%6) \\
\hline Ultraviolet sterilization & Microorganism & $\begin{array}{l}\text { High efficiency, safe and convenient, no residual toxicity, } \\
\text { no pollution, small resistance }\end{array}$ & Poor dynamic sterilization effect & $82.90 \%$ \\
\hline $\begin{array}{l}\text { Activated carbon } \\
\text { adsorption }\end{array}$ & $\begin{array}{l}\text { All the pollutants except biological } \\
\text { pollutants }\end{array}$ & $\begin{array}{l}\text { Wild sources, bigger pollutant purifying range, not easy } \\
\text { to cause the secondary pollution }\end{array}$ & $\begin{array}{l}\text { Saturated regeneration problems, resistance is bigger, mineral processing, } \\
\text { is not good }\end{array}$ & \\
\hline Plasma & All indoor pollutants & Big range of pollutants & Cannot completely degrade pollutants and produce by-products & $66.70 \%$ \\
\hline Negative ions & Particles microorganism & $\begin{array}{l}\text { Accelerate metabolism, strengthen cell function, effective } \\
\text { to some disease }\end{array}$ & Produce ozone, cause second pollution, deposition of dust damage the wall & $73.40 \%$ \\
\hline Photocatalysis & $\begin{array}{l}\text { TVOC, microorganisms and other } \\
\text { inorganic gaseous pollutuants }\end{array}$ & $\begin{array}{l}\text { Wide range of purification, mild reaction conditions, no } \\
\text { adsorption saturation phenomenon, long service life }\end{array}$ & $\begin{array}{l}\text { Compared to the activated carbon adsorption technology, slower } \\
\text { purification process, easy to cause the secondary pollution if response is } \\
\text { not completed }\end{array}$ & $\begin{array}{l}\text { 75\% (some may only } 30 \% \text { or } \\
\text { even negative) }\end{array}$ \\
\hline
\end{tabular}

\subsection{Synergistic effect by integrating with other air purification technologies}

Synergistic effect is an effect that arises between two or more agents, entities, factors, or substances that can produce an effect greater than the sum of their individual effects (Corning, 2003). Taking advantage of the synergistic effect can help to avoid the adverse consequences that the combination of multiple purification technologies might produce. Similarly, it can maximize the strengths and minimize the weakness of individual purification techniques, such as adsorption photochemical catalysis, non-thermal plasma photocatalysis, etc.

In general, the rate of photocatalytic reaction is slow when the indoor pollutant concentration is low. Integrating adsorption and photochemical catalysis can improve the catalytic reaction rate as adsorption provides photocatalysis with relatively high concentrations of indoor contaminants. Besides, the photocatalysis degradation of concentrated pollutants realizes the insitu regeneration of the adsorbent (Paz, 2010; Mo and Ye, 2009; Yoneyama and Torimoto, 2000). For example, the ACF (activated carbon fibre) - TiO2 photocatalytic technology, which combines activated carbon dsorption and photocatalysis, forms a virtuous cycle of adsorption - photocatalysis - adsorption that can achieve efficient indoor air purification.

The principle of non-thermal plasma-photocatalysis is as follows:during the process of the plasma discharge, highenergy particles on anexcited upper level can execute a downward transition and produce UV radiation, which can be used as UV light source for photocatalysis. Then, electron-hole pairs are formed in the semiconductor, which triggers a series of REDOX (reduction-oxidation) reaction. The photogenerated holes would produce $\mathrm{OH}-\mathrm{free}$ radicals on the catalyst surface, which is able to oxidize and decompose pollutants. Additionally, the catalyst can selectively react with the by-products of the plasma to reduce the possibility of secondary pollution (Lu., Wang, \& Sheng, 2009; Van Durme, Dewulf, Sysmans, Leys, \& Van Langenhove, 2007; Xiaoyu, Hong, \& Jing, 2009). Therefore, the nonthermal plasma-photocatalysis technique can not only remove contaminants more quickly and effectively, but also reduce the by-products and energy consumption during the reaction.

Table 10 lists the main air purifier brands and the application of purification techniques. Products in the market generally combine a variety of purification technologies to complement each other and to make up for the shortcomings of individual techniques. Therefore, the synergistic effect among different air purification technologies can bring about more efficient and much improved purification. 


\begin{tabular}{|c|c|c|c|c|c|c|c|c|}
\hline \multicolumn{9}{|l|}{ Technique } \\
\hline & & Filtration & Adsorption & $\begin{array}{l}\text { Electrostatic } \\
\text { precipitation }\end{array}$ & $\begin{array}{l}\text { Anion } \\
\text { technology }\end{array}$ & Plasma Technology & $\begin{array}{l}\text { Photocatalysis purifying } \\
\text { technology }\end{array}$ & $\begin{array}{l}\text { Water washing } \\
\text { purification }\end{array}$ \\
\hline \multirow[t]{3}{*}{ Europe } & Philips & $\sqrt{ }$ & $\sqrt{ }$ & & & & & $\sqrt{ }$ \\
\hline & Blueair & $\sqrt{ }$ & $\sqrt{ }$ & $\sqrt{ }$ & & & & \\
\hline & Electrolux & $\sqrt{ }$ & $\sqrt{ }$ & & & $\sqrt{ }$ & & \\
\hline \multirow[t]{3}{*}{ Japan } & Sharp & $\sqrt{ }$ & $\sqrt{ }$ & & & Plasmacluster & & \\
\hline & Panasonic & $\sqrt{ }$ & $\sqrt{ }$ & & Nano Ion Water & & & $\sqrt{ }$ \\
\hline & Daikin & $\sqrt{ }$ & & $\sqrt{ }$ & $\sqrt{ }$ & $\sqrt{ }$ & $\sqrt{ }$ & \\
\hline $\begin{array}{c}\text { the United } \\
\text { States }\end{array}$ & Honeywell & $\sqrt{ }$ & $\sqrt{ }$ & & & & & \\
\hline \multirow[t]{4}{*}{ China } & Yadu & $\sqrt{ }$ & $\sqrt{ }$ & & $\sqrt{ }$ & & $\sqrt{ }$ & $\sqrt{ }$ \\
\hline & Broad & $\sqrt{ }$ & $\sqrt{ }$ & $\sqrt{ }$ & & & & \\
\hline & Lexy & $\sqrt{ }$ & $\sqrt{ }$ & & & $\sqrt{ }$ & & $\sqrt{ }$ \\
\hline & TCL & $\sqrt{ }$ & $\sqrt{ }$ & & & & $\sqrt{ }$ & \\
\hline South Korea & Samsung & $\sqrt{ }$ & $\sqrt{ }$ & & & $\sqrt{ }$ & & \\
\hline
\end{tabular}

\section{Research development in sustainable and healthy building ventilation}

\subsection{1. Indoor air quality}

Filtration technology is currently the integral part of air purification techniques that focus on particulate matters. The most common example is the fibrous filter (Podgórski, Bałazy, \& Gradon, 2006). Air filters can be divided into four types according to the particle filtration efficiency: pre filter, medium filter, high efficiency particulate air (HEPA) filter and ultra-low particulate air (ULPA) filter (Ahn et al., 2006; Schroth, 1996). The filtration efficiency of ULPA filter is over $99.999 \%$ with a particle diameter of 0.12-0.17- $\mu \mathrm{m}$ (Jamriska, Martin, \& Morawska, 1997). Similarly, HEPA material has a strong ability for trapping particles as it can remove $99.97 \%$ of particulate matter, smog and bacteria that have a size over $0.3 \mu \mathrm{m}$, whereas the efficiency of medium filter is only $60-90 \%$ (Hanley, Ensor, Smith, \& Sparks, 1994; Chuaybamroong et al., 2010).

Most air purifiers in the market adopt HEPA filters, as they are internationally recognized as the most efficient filters capturing particles of different diameters. HEPA filters are designed to be over $99.99 \%$ efficient and are used in theatres, hospitals, respirators, vehicles, etc.(Brincat et al., 2016). Non-woven nano-fibre material is an emerging filtration technique with an extremely high filtering efficiency. They are comparable to HEPA filters or are even superior to them at smaller particle size (Wang, Raza, Sun, \& Ding, 2013). Glass fibre filter is another mature filtration technique with a high efficiency (99.0\%), which is similar to that of the HEPA filter (John and Reischl, 1978). Besides, glass and plastic (such as Dacron, Teflon and polypropylene), fibres can be made of stainless steel. Wire mesh filter provides good filtration efficiency down to sizes of $2 \mu \mathrm{m}$ to $10 \mu \mathrm{m}$ (Setekleiv, Eddie, \& Hallvard, 2012).

Another filtration technique, Trombe wall, can achieve a healthy indoor air quality even in polluted urban environments. According to Imbabi (2006), Trombe wall has a very high air filtration efficiency when the outdoor air is lead through breathing wall panels (see Fig. 2). When a breathing wall is used as a particulate filter in a building, it is necessary to ensure that the channels remain open and not get plugged. In these cases, depth filtration is applied as it captures particles both on the surface and within the thickness of the filter. Trombe wall employing such media can ensure that particles with diameter greater than 10 $\mu \mathrm{m}$ and less than $0.01 \mu \mathrm{m}$ are captured on the surface, while the particles in the intermediate-range are caught within the depth of the material. A new, layered dynamic insulation wall structure is proposed to achieve depth rather than surface filtration. For example, a $200 \mathrm{~mm}$ depth dynamic insulation layer has been presented with an extremely low blocking rate (60 years' service life) and predicted high filtration efficiency (99.4\%) of PM10 (Imbabi and Peacock, 2004). However, Trombe wall is ineffective against particles of $0.1-1 \mu \mathrm{m}$ diameter. 

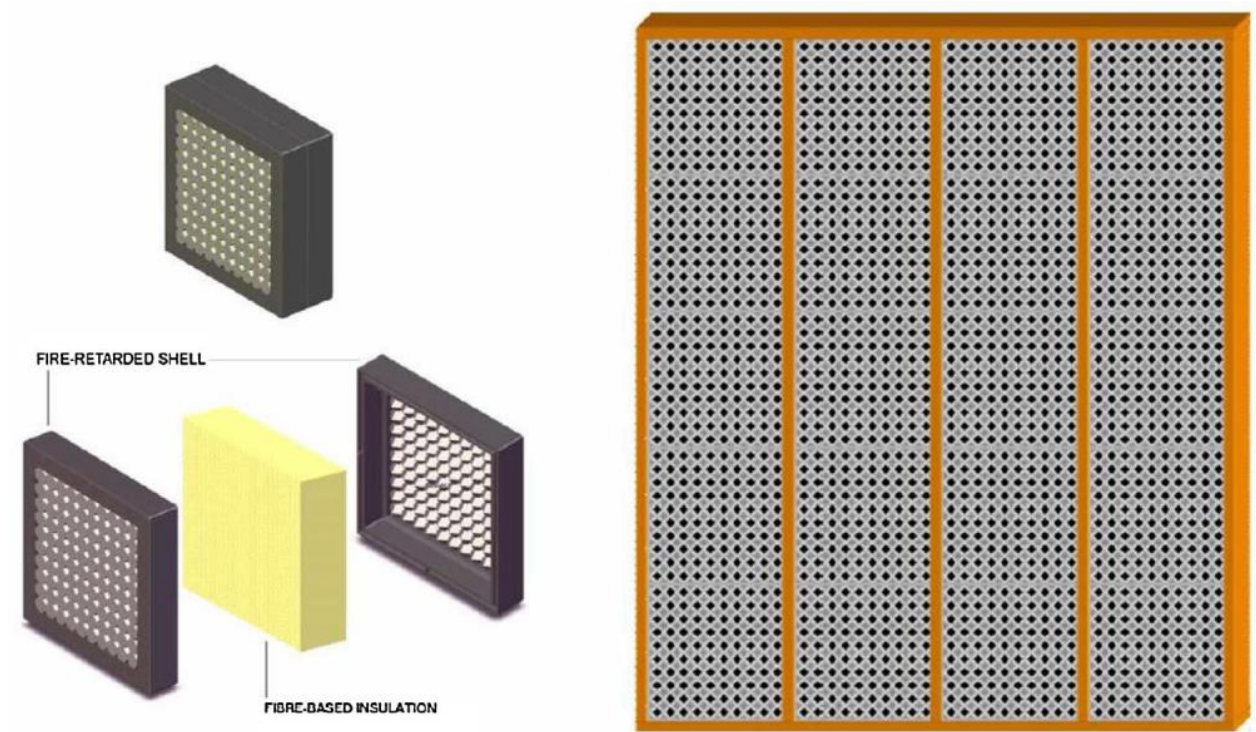

Fig. 2. Modular breathing panels in framed construction courtesy of EBP Ltd. Source from:

Imbabi (2006)

Biofiltration technique biologically degrades air contaminants bytaking advantage of the process of microbiotic oxidation. The process is as follows: when polluted air flows through a biofilter, the pollutants are degraded by bacteria and fungi that are immobilized in the biofilm on the surface of the packed bed. Consequently, a large area is typically required for the filtration of large airflows, which is one of the main disadvantages of this technique. The industry has been commonly applying biofilters for many years, as an earlier research proved its effectiveness in odour control for a wide range of volatile organic compounds (VOCs) such as sulfur compounds and amines (Joseph, Marc, \& Todd, 1999). Other common uses of biofiltration include purification of surface runoff and waste water processing.

Cai and Sorial (2009) reported that an integrated system utilizing trickling-bed air biofilters with cyclic adsorption/desorption beds can maintain removal efficiency of a mixture of volatile organic compounds (VOCs) consistently at $99 \%$ under fluctuated feeding conditions, while the employed loading is lower than critical loading, $34.0 \mathrm{~g} /\left(\mathrm{m}^{3} \mathrm{~h}\right)$. The mixture of volatile organic compounds (VOCs) includes toluene, styrene, methyl ethyl ketone (MEK) and methyl isobutyl ketone (MIBK). Similarly, according to Aly Hassan and Sorial (2011), integrating trickle bed air biofilters with cyclic adsorption/desorption beds, the removal efficiency of $n$-hexane would fluctuated from $50 \%$ to $77 \%$ according to the loading rate, while in the case of benzene it can achieve at least $85 \%$ efficiency.

Active Living Walls (ALW), behaved as 'passive' biofiltration systems allowing the development of vegetation in a vertical surface attached to building facades or indoor walls. They also contribute to better microclimates. The technology is known as 'the most easily adapted to mechanically ventilated building or on the pit fans of naturally ventilated buildings'. Thus, it can be integrated with the building's air conditioning and ventilation systems. Air is forced to pass through the ALWs to take advantages of their biological capacity and evaporative cooling potential to cool, purify and humidify air, which in turn potentially reduces ventilation requirements (Arsenault, Faia, Ncarb, Leed AP, \& Darlington, 2012; Pérez-Urrestarazu, Fernández- Cañero, Franco, \& Egea, 2016). The schematic of indoor ALW is shows in Fig. 3. ALWs are a natural alternative to energy consuming artificial air filters. Arsenault et al. (2012) conducted an experiment in which three common indoor organic pollutants were filtered for 4 weeks. The results show that the botanical components removed significant amounts of air pollutants: $80 \%$ formaldehyde, $50 \%$ toluene and $10 \%$ trichloroethylene reduction were achieved by a single pass of the air through a $5 \mathrm{~cm}$ thick living wall. 


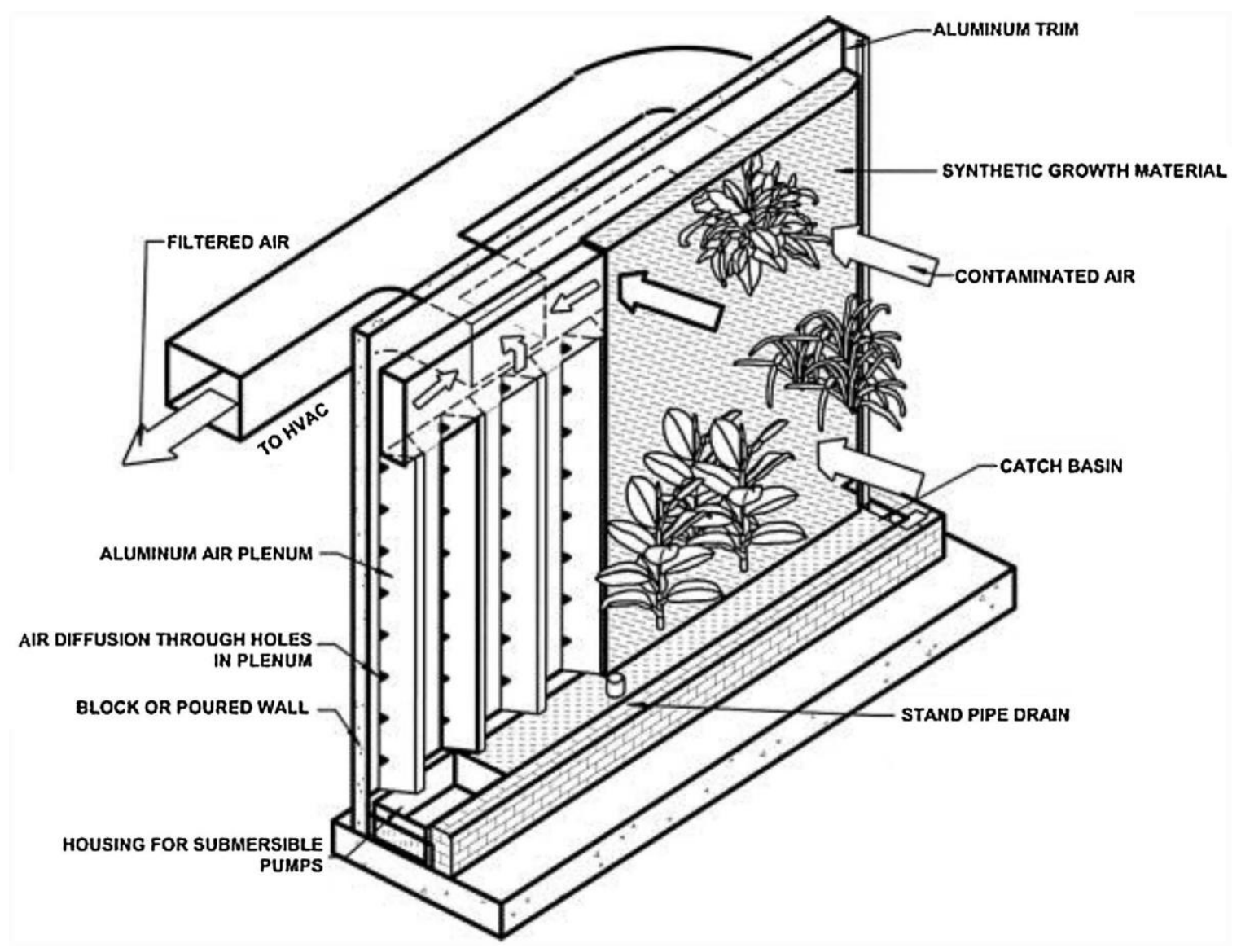

Fig. 3. Schematic of indoor biofiltration system. Source from: Soreanu et al. (2013).

ALWs attached to the facades of buildings are called bio-façade. This relatively new architectural concept is illustrated on Fig. 4. It creates a path towards making cities more environmentally sustainable. Bio- façade offers multiple benefits that includes air purification, energy conservation, etc. at both urban scale and building scale (benefiting both neighborhoods and the occupants of the buildings as well). The benefits of bio-facades are listed in Table 11 in detail. Studies indicated that the bio-facades' air filtering and oxygenating abilities greatly benefit people suffering from breathing diseases caused by air pollution (Wood, Bahrami, \& Safarik, 2014).

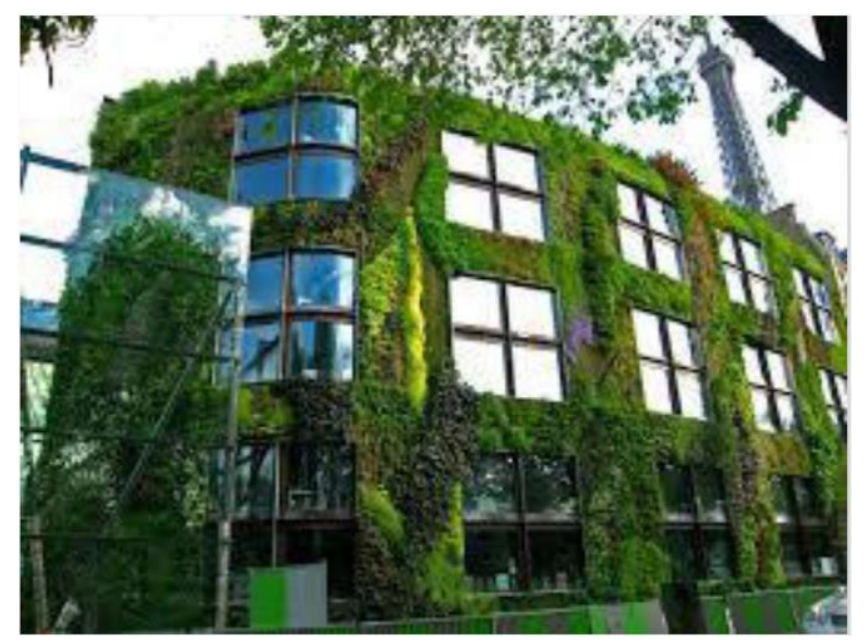

Fig. 4. Example of bio-façades.Source from: Othman and Sahidin (2016). 
Table 11

Benefits of bio-façade in urban and building scale (Adapted from Antony Wood et al. (2014)).

\begin{tabular}{ll}
\hline Urban Scale & Building Scale \\
\hline Reduction of the Urban Heat Island Effect & Improvement of Building Energy \\
& Efficiency \\
Improvement of Air Quality & Internal Air Quality, Air Filtration \\
& and Oxygenation \\
Sequestering of Carbon & Health Benefits \\
Aesthetic Appeal & Envelop Protection \\
Psychological Impact on Urban Dwellers & Interior Noise Reduction \\
Providing Biodiversity and Creating & Agricultural Benefits \\
$\quad$ Natural Animal Habitats & Increasing Property Value \\
Sound Deadening & Sustainability Rating System Credits \\
\hline
\end{tabular}

According to Wang and Zhang (2011), the Dynamic Botanical Air Filtration system (DBAF) is best in removing indoor VOCs, especially toluenes and formaldehydes, even when there are no plants in the bed. Higher initial removal efficiency can be achieved with plants, as over 33\% of toluene and $90 \%$ of formaldehyde is removed during the first four days of a short-term test period. The results of a long-term performance test showed that DBAF maintained it efficiency during the 300-day test period and at the end, it had the same level of single pass removal efficiency. Office experiments have demonstrated that with the use of DBAF, the percentage of outdoor air supply to the total air supply can be reduced from $25 \%$ to $5 \%$. When toluene and formaldehyde are the target contaminants, the reduction of the ventilation rate would not affect indoor air quality adversely. The schematics of a dynamic botanical air filtration system are shown on Fig. 5.
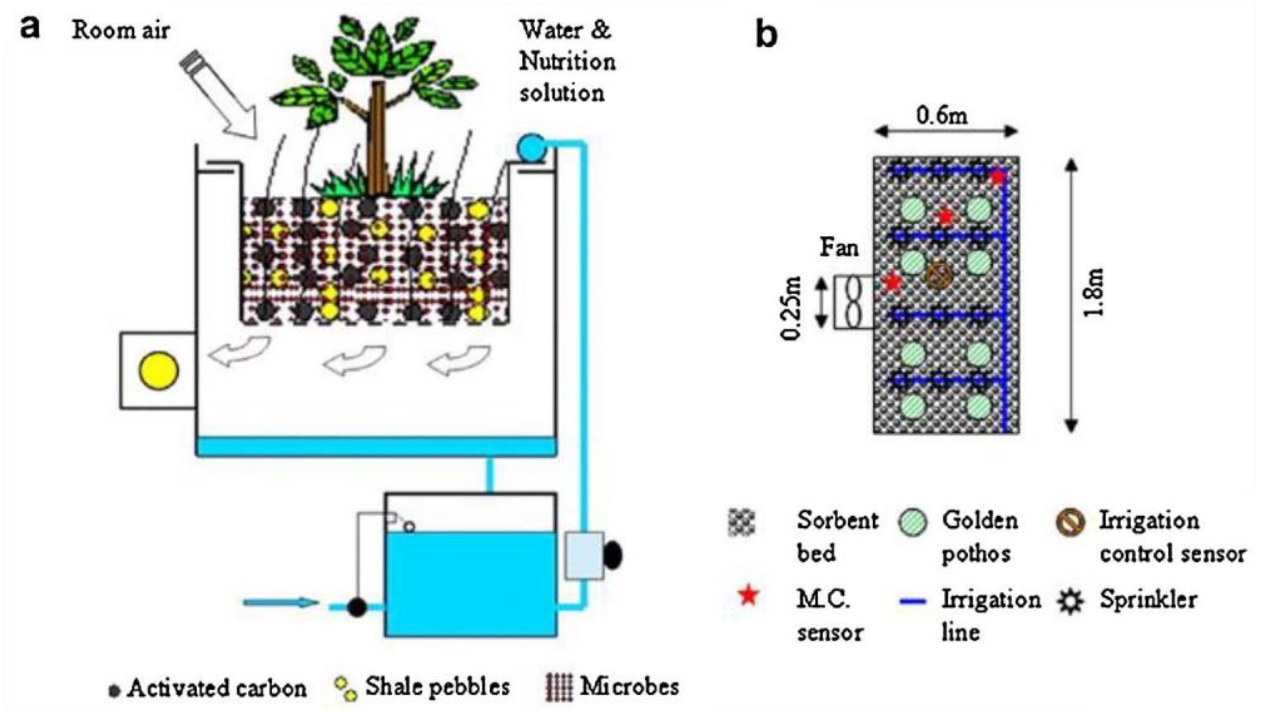

Fig. 5. Schematic of dynamic botanical air filtration system: (a) side view, (b) top view. Source from: Wang and Zhang (2011).

Adsorption-based granular activated carbon filter (GAC) is a common technology for removing gas phase contaminants. Khazraei Vizhemehr, Haghighat, Lee, and Kholafaei (2015) found that the GAC filter performed best in removing toluene (both in single and mixture scenarios), which was followed by $n$-hexane and methyl ethyl ketone (MEK). The GAC filter's removal performance of mixture gas phase contaminants was significantly reduced compared to that of single gases, since different compounds of a gas mixture would compete for the same free space on the carbon media. Among the different physical properties of indoor contaminant, the removal performance and service life of tested GAC filters were in direct proportion to the contaminant's molecular weight.

Although filtration technology has now reached an advanced level, filter colonization is still a common problem among physical filters as they only trap and not deactivate or destroy bacteria and fungi. Furthermore, filters generally provide a good medium for bacteria and fungi to grow on, as a result of the captured dust and other organic 
particles (see Fig. 6). Consequently, it is possible for fungi to utilize the clutched organic particles as food source, and grow on the filter's clean side and produce spores that are then spread and result in downstream air pollution. As Maus, Goppelsröder, and Umhauer (2001) reported, constant, strong air flow can suppress fungal growth. However, the trapped atmospheric dust may serve as nutrient to fungi not exposed to air flow and with adequate humidity present. This process can turn the filter into a secondary source of pollutants. Price, Simmons, Crow, and Ahearn (2005) pointed out that this is a cross contamination problem that poses a considerable health risk in places such as hospitals. The implication of this might be that in order to keep physical filters free from fungal growth, they should be combined with sterilization systems.

(A) Discolored patches on the filter material of filter load side (arrows). (B) Brown fungal colony on the surface of filter supply side (arrow). (C) Fungi stained filter load side, hyphal elements on the filter medium surface, showed by laser confocal microscopy. (D) Fungi stained the cross section of filter medium, hyphae penetrating the filter matrix from the load side (left) towards the supply side, showed by laser confocal microscopy. (E) Fungi stained filter supply side, showed by laser confocal microscopy (Adapted from Price et al., 2005).
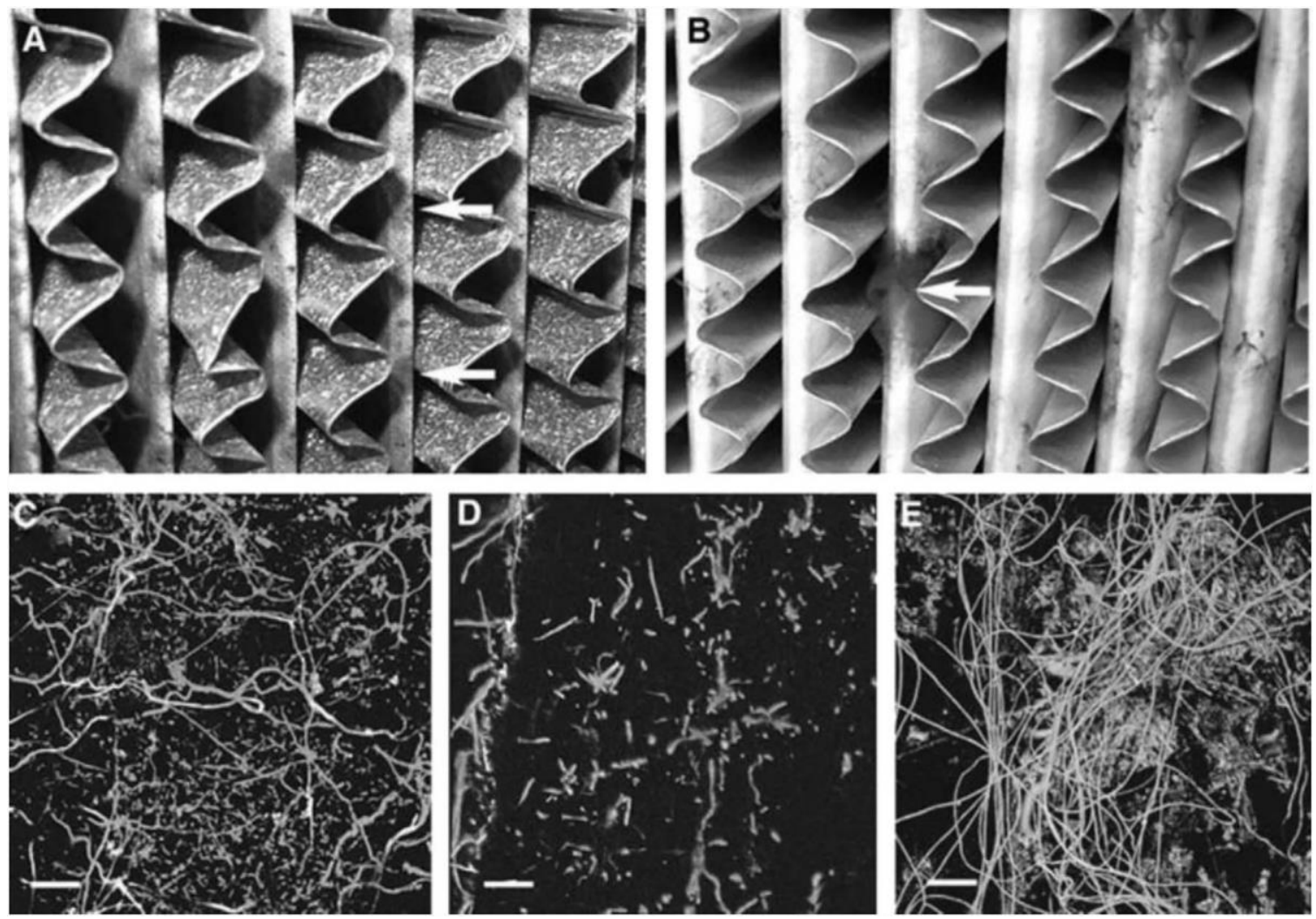

Fig. 6. Fungal growth with penetration of microglass filter medium of a galvanized steep framed HEPA filter.

Filters can exhibit antimicrobial properties when integrated with antimicrobial agents, for example Silver (Ag). Montazer and Malekzadeh (2012) reported on the antibacterial properties of nano- fibres and nylon nanofibre with Ag that can be used against Staphylo- coccus aureus and Escherichia coli (Gram-negative). Zhang, Luo et al. (2011) pointed out that electrospun nanofibres membranes (ENMs) contain Ag particles are highly active against microbes, while also possess adequate transport properties for air filtration applications. These nanofiber-based filtration technologies can reduce the content of bacteria in the air. The ability of nanofibres filters to remove nano- particles and volatile organic compounds from the air is also very promising (Ezhilvalavan et al., 2014). In order to maintain indoor air cleanliness, the majority of advanced air filtration technologies are combining with other air purification technologies for synergistic effect to achieve high efficiency, increase energy conservation and lessen by- product pollution, etc.

Electrostatic air filter (ES) is a type of air filter that combines electrostatics and filtration and washable. The Schematic of ES is shown in Fig. 7. Electrostatic Air filters purify the air by static electricity, a naturally and safe occurring phenomenon. Airborne particulates are attracted and trapped by the static charge when air flows through a maze of static prone fibres until released by washing. According to Air Commander Permanent Electrostatic Air Filters company, all of Air Commander Electrostatic Air Filters contain an EPA (Environmental 
Protection Agency) registered anti-microbial material to inhibit mould and bacteria growth on the air filter surface. ES filter provides an effective and efficient way to reduce the number of the particles that are smaller than one micron, such as pollen, dust, bacteria, mould spores, pet dander and smoke. The filtration efficiency of $82 \%$ to $94 \%$ can be achieved by different types of Electrostatic Air Filters (see Table 12).

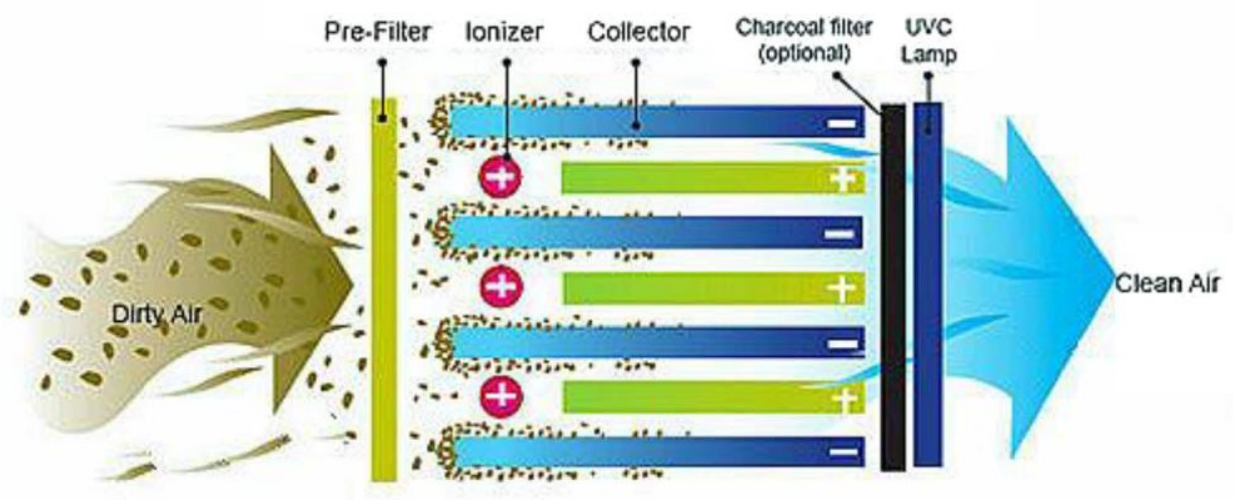

Fig. 7. Schematic of Electrostatic air filter.

Table 12

Summary of different types of Electrostatic Air Filters (Adapted from Official website of Air-care (2016)).

\begin{tabular}{|c|c|c|c|c|c|c|}
\hline Parameters & $\begin{array}{l}\text { Gold } \\
\text { Frame } 94\end{array}$ & $\begin{array}{l}\text { Gold } \\
\text { Frame } 82\end{array}$ & $\begin{array}{l}\text { Silver } \\
\text { Frame } 94\end{array}$ & $\begin{array}{l}\text { Silver } \\
\text { Frame } 82\end{array}$ & Flexible Frame 94 & Flexible Frame 82 \\
\hline Filtration Efficiency & $94 \%$ & $82 \%$ & $94 \%$ & $82 \%$ & $94 \%$ & $82 \%$ \\
\hline Dust Holding Capacity & $165 \mathrm{~g}$ & $119 \mathrm{~g}$ & $165 \mathrm{~g}$ & $119 \mathrm{~g}$ & $165 \mathrm{~g}$ & $119 \mathrm{~g}$ \\
\hline Air Flow Resistance & 0.12 & 0.08 & 0.12 & 0.08 & 0.12 & 0.08 \\
\hline Frame Quality & Excellent & Excellent & Good & Good & Flexible & Flexible \\
\hline UV Resistant & Yes & No & Yes & No & Yes & Yes \\
\hline MERV Rating & 8 & 6 & 8 & 6 & 8 & 6 \\
\hline
\end{tabular}

A specific application of electrostatic technology is Electrostatic Precipitators (ESPs), which are usually used in industry and are effective at destroying fungal spores, but useless for viruses (Zheng, Liu, \& Yan, 2013). This is because ESPs works best with particle sizes above $0.1 \mathrm{~mm}$. The overall efficiency of ESPs is much lower than that of fibre mats and HEPA filters (Brincat et al., 2016). Thus, electrostatic precipitators are regularly used in scenarios where particulates present in the air need to be cleaned by deposition, for example smoke stacks, rather than in hospitals. Though, ESPs is known to produce small amounts of ozone in the air stream, it is reported that the ozone production can be reduced by adopting alternating voltage (Lin, Chang, Lien, \& Kuo, 2011).

Similarly, spore membranes are damaged and destroyed when they pass through the plasma. Thermal plasma is one of the processes for the removal of noxious compounds (especially VOCs) from industrial applications. It is proved applicable for wastes containing high concentrations of organic components, but is not economical at low concentration levels. Therefore, it is practically impossible for thermal plasma to be applied for indoor air treatment and be integrated with buildings mechanical ventilation systems (Bahri and Haghighat, 2014). Cold plasma (or nonthermal plasma) air filtration has been showed to work efficiently with either fungal spores or airborne bacteria. It can achieve $85 \%-98 \%$ decontamination even with a very low exposure time (0.06 s) (Gallagher et al., 2007, Liang et al., 2012). According to Subrahmanyam, Magureanu, Renken, and Kiwi-Minsker (2006) this technology is effective at volatile organic compounds (VOC) and has been shown to remove ethylene from the air. Thus, it is usually applied in high-risk hospital areas (Kapustina and Volodina, 2003). However, Park, Byeon, Yoon, Park, and Hwang (2011) reported that ozone and nitrogen oxides would be generated through the working process of cold plasma, the influence of these reactive chemicals should be evaluated when cold plasma filter are to be applied. Experimental results of Bahri, Haghighat, Rohani, and Kazemian (2016) showed that applying inner electrode at a greater length increase the residence time and formats larger amounts of ozone for a specific input energy. Nevertheless, as it has been discussed before, the chemical by-products of cold plasma can be reduced or eliminated by the synergistic effect their combination with other air purification technologies, such in the case of non-thermal plasma-photocatalysis.

Photocatalytic oxidation is a promising technology that has the potential to improve indoor air quality and to 
deliver an energy- efficient solution for HVAC applications (Aghighi, Haghighat, Zhong, \& Lee, 2014; Zhong and Haghighat, 2015a). It efficiently kills bacteria and viruses, and also has a high remove rate for VOCs. However, it is not effective in the case of suspended particles. Formaldehyde and acetaldehyde are two common by-products of PCO. The toxic by-products of PCO air cleaner makes it necessary to combine chemisorbed scrubber to reduce the potential health risks and to improve indoor air quality (Zhong, Haghighat, Lee, \& Lakdawala, 2013). According to Farhanian and Haghighat (2014) ultraviolet photocatalytic oxidation (UV-PCO) has been recognized as a unique technology for indoor VOCs decomposition, which also minimize the building energy consumption. The experiment of Farhanian, Haghighat, Lee, and Lakdawala (2013) showed that by-products can be reduced at higher flow rate, but with lower removal efficiency, and increased number of reactors improves reaction section further leads to higher ethanol removal efficiency, less partial oxidation, lower amount of by- products and the complete mineralization of acetaldehyde. Aghighi and Haghighat (2015) developed a new nano-TiO2 photocatalyst to improve the performance of UV-PCO systems in indoor air applications. The catalysts were challenged with ethanol as primary test compound and the efficiency was evaluated with different VOCs. The results showed the new nano-TiO2 photocatalyst has a better removal efficiency compared to other catalysts under similar experimental conditions. Table 13 provides a summary of various air filtration techniques in terms of effective particles and filtration efficiency.

Table 13 Summary of air filtration techniques.

\begin{tabular}{|c|c|c|c|c|c|}
\hline \multicolumn{2}{|c|}{ Air filtration technique } & \multirow{2}{*}{$\begin{array}{l}\text { Effective particles (Diameter) } \\
>0.3 \mu \mathrm{m}\end{array}$} & \multirow{2}{*}{$\begin{array}{l}\text { Efficiency } \\
60-90 \%\end{array}$} & \multirow{2}{*}{$\begin{array}{l}\text { Reference } \\
\text { Hanley et al. (1994) }\end{array}$} & \multirow[t]{2}{*}{ Remarks } \\
\hline Fibrous filter & Medium filter & & & & \\
\hline & HEPA & $>0.3 \mu \mathrm{m}$ & $>99.99 \%$ & Brincat et al. (2016) & \\
\hline & ULPA & $0.12-0.17-\mu \mathrm{m}$ & $>99.999 \%$ & Jamriska et al. (1997) & \\
\hline & Glass fibre & $2 \mu \mathrm{m}$ to $10 \mu \mathrm{m}$ & $99.00 \%$ & John and Reischl (1978) & \\
\hline & Nano-fibre & $<0.3 \mu \mathrm{m}$ & $>99.99 \%$ & Wang et al. (2013) & \\
\hline \multicolumn{2}{|l|}{ Trombe wall } & $>10 \mu \mathrm{m} \&<0.01 \mu \mathrm{m}$ & $99.4 \%$ for PM10 & Imbabi and Peacock (2004) & $\begin{array}{l}\text { Useless for } 0.1-1 \mu \mathrm{m} \\
60 \text { years' service life }\end{array}$ \\
\hline \multirow[t]{2}{*}{ Biofilter } & $\begin{array}{l}\text { Dynamic botanical air } \\
\text { filtration system }\end{array}$ & Mixture of VOCs & $\begin{array}{l}>33 \% \text { for toluene } \& 90 \% \text { for } \\
\text { formaldehyde }\end{array}$ & Wang and Zhang (2011) & $\begin{array}{l}\text { Effective odor control } \\
\text { method }\end{array}$ \\
\hline & $\begin{array}{l}\text { Integrated biofiltration } \\
\text { system }\end{array}$ & & $99 \%$ & Cai and Sorial (2009) & \\
\hline \multirow[t]{2}{*}{$\begin{array}{l}\text { Electrostatic } \\
\text { Air filter }\end{array}$} & $\begin{array}{l}\text { Electrostatic } \\
\text { Air filter }\end{array}$ & $<0.1 \mathrm{~mm}$ & $82 \%-94 \%$ & $\begin{array}{l}\text { AIR COMMANDER official } \\
\text { website }\end{array}$ & \\
\hline & Electrostatic Precipitators & $>0.1 \mathrm{~mm}$ & lower than HEPA & Zhuang et al. (2000) & $\begin{array}{l}\text { Produce small amounts of } \\
\text { ozone }\end{array}$ \\
\hline \multicolumn{2}{|c|}{ Cold plasma air filter } & $\begin{array}{l}<0.1 \mathrm{~mm} \\
\text { also effective at VOC }\end{array}$ & $85 \%-98 \%$ & $\begin{array}{l}\text { Liang et al. (2012); Gallagher } \\
\text { et al. (2007) }\end{array}$ & $\begin{array}{l}\text { Produce ozone \& nitrogen } \\
\text { oxides }\end{array}$ \\
\hline
\end{tabular}

\subsection{Performance in terms of efficiency and pressure drop}

The filtration efficiency of common fibrous filter grows with the increase of the filter's solidity, which is directly proportional to the air pressure drop. Thus, in order to achieve high filtration efficiency, a high pressure fall is inevitable for general air filters - an effect that causes a large energy losses (Fisk, Faulkner, Palonen, \& Seppanen, 2002). For example, the pressure drop of HEPA (99.97\% efficiency) and ULPA (99.999\% efficiency) are both around $25-50$ mmAq, while that of a medium filter with 60-90\% efficiency is 15-30mmAq (Hanley et al., 1994; Jamriska et al., 1997; Chuaybamroong et al., 2010). Similarly, Li, Shen, and Li (2016) indicated that the filtration efficiency for all particle sizes is improved with the use of large number of thin fibres with higher pressure drop. However, the best filter should offer the least pressure drop with the highest filtration efficiency. In order to solve this problem, extensive researches have been conducted focusing predominantly on nanofibers.

Yang, Zhang, Zhao, Yu, and Ding (2015) developed a new nanofibre with excellent air filtration performance via continuous electrospinning. It is a sandwich structured polyamide 6/polyacrylonitrile/polyamide-6 (PA-6/PAN/PA6) composite membrane with two-dimensional (2D) nanonets and stable cavity structures. In contrast to HEPA and ULPA filters, the as-prepared PA-6/PAN/PA-6 composite membranes successfully break away from the potential risk caused by unexpected electret failure. Furthermore, it is proved to make a pretty major leap towards high filtration efficiency of $99.9998 \%$ with a low pressure drop (117.5 Pa) for 300-500 nm airborne particles.

Similarly, Liu, Zhang, Wang, Yu, and Ding (2015) constructed an original bio-based polyamide-56 nanofibre/nets (PA-56 NFN) membrane with bimodal structure by one-step electrospinning/netting to improve air filtration efficiency. Compared to PA-6/PAN/PA-6 composite membrane, it is also composed of 2D ultrathin nanonets and stable cavity structures. Because of the integrated properties of bonded scaffold, small aperture and high porosity, the final PA-56 NFN membrane has $99.995 \%$ efficiency with a low pressure drop of $111 \mathrm{~Pa}$. It showed a long service 
life with dust-cleaning regeneration ability and large dust holding capacity of $49 \mathrm{~g} / \mathrm{m}^{2}$. Its dust-cleaning regeneration cycle and the relationship between filtration efficiency and pressure drop are illustrated below (Fig. 8).

According to Wang and Pan (2015), a hierarchical structured nano-sized/porous poly (lactic acid) (PLA-N/PLA-P) composite fibrous membrane was fabricated via electrospinning for effective air filtration. The resulting PLA-N/PLA$\mathrm{P}$ double-layer structured membrane with a mass ratio of $1 / 5$ presented a relatively low pressure drop of $93.3 \mathrm{~Pa}$ and an excellent air filtration efficiency of $99.999 \%$ at the face velocity of $5.3 \mathrm{~cm} / \mathrm{s}$. As Fig. 9 shows, its performance was superior to that of HEPAs.

Compared with fibrous filters, a high pressure drop is avoidable for electrostatic (ES) air filter as the electrostatic interaction between fibres and particles can dramatically enhance the filtration efficiency without pressure drop increase. Particularly, it is useful to improve the filtration efficiency for particles with size range of $0.15-0.5 \mu \mathrm{m}$ (Aussawasathien, Teerawattananon, \& Vongachariya, 2008). Wen, Wang, Krichtafovitch, and Mamishev (2015) proved that the collection efficiency of electrostatic precipitator air filter with foam-covered collecting electrodes could achieve $99 \%$ efficiency at a specific corona voltage, which is not lower than that of an HEPA filter. But after filtering efficiency achieved $99 \%$, raising the corona voltage would increase the power consumption rather than increase filtering efficiency. Also, it is demonstrated that the highest efficiency does not necessarily appear at the most extreme airflow velocity. Extremely high airflow velocity increases the chance of particles being blown out of the channel, rather than being captured, while low airflow velocity increases the possibility of spark discharge between the exciting electrodes and corona. Hence, a moderate airflow velocity is desirable.

An antimicrobial nanoparticle-coated electrostatic air filter with high filtration efficiency and low pressure drop was presented by Sim, Park, Bae, and Jung (2015). The application of corona discharge electrification system increased the air filtration efficiency, for example, the deposition efficiency of ES filter was about $12 \%$ than that of Non-ES filter. The antimicrobial activity of ES air filter was more than $99 \%$ with filtration efficiency of $92.5 \%$ (for a $300-\mathrm{nmKCl}$ aerosol) and a pressure drop of $0.8 \mathrm{mmAq}$, at the face velocity of $13 \mathrm{~cm} / \mathrm{s}$. A summary is presented in Table 14 for air filters' performance in terms of filtration efficiency and pressure drop.

Table 14 Air filters' performance in terms of efficiency and pressure drop.

\begin{tabular}{|c|c|c|c|c|}
\hline Air filtration technique & & Efficiency & Pressure drop & Reference \\
\hline \multirow[t]{6}{*}{ Fibrous filter } & ULPA & > $99.999 \%$ & $25-50 \mathrm{~mm} \mathrm{Aq}$ & Hanley et al. (1994) \\
\hline & HEPA & $>99.99 \%$ & $25-50 \mathrm{~mm} \mathrm{Aq}$ & Chuaybamroong et al. (2010) \\
\hline & Medium filter & $60-90 \%$ & $15-30 \mathrm{mmAq}$ & Jamriska et al. (1997) \\
\hline & A sandwich structured nanofibre & $99.9998 \%$ & $117.5 \mathrm{~Pa}$ & Yang et al. (2015) \\
\hline & Bio-based polyamide-56 nanofibre & $99.995 \%$ & $111 \mathrm{~Pa}$ & Bowen Liu et al. (2015) \\
\hline & Hierarchical structured nanofibre & $99.999 \%$ & 93.3Pa & Wang and Pan (2015) \\
\hline \multirow[t]{2}{*}{ Electrostatic (ES) air filter } & Electrostatic precipitator air filter & $99 \%$ & - & Wen et al. (2015) \\
\hline & Antimicrobial nanoparticle-coated electrostatic air filter & $92.50 \%$ & $0.8 \mathrm{~mm} \mathrm{Aq}$ & Sim et al. (2015) \\
\hline
\end{tabular}

\section{PA-56 Nanofiber/nets Membrane with Filtration Regeneration Ability}

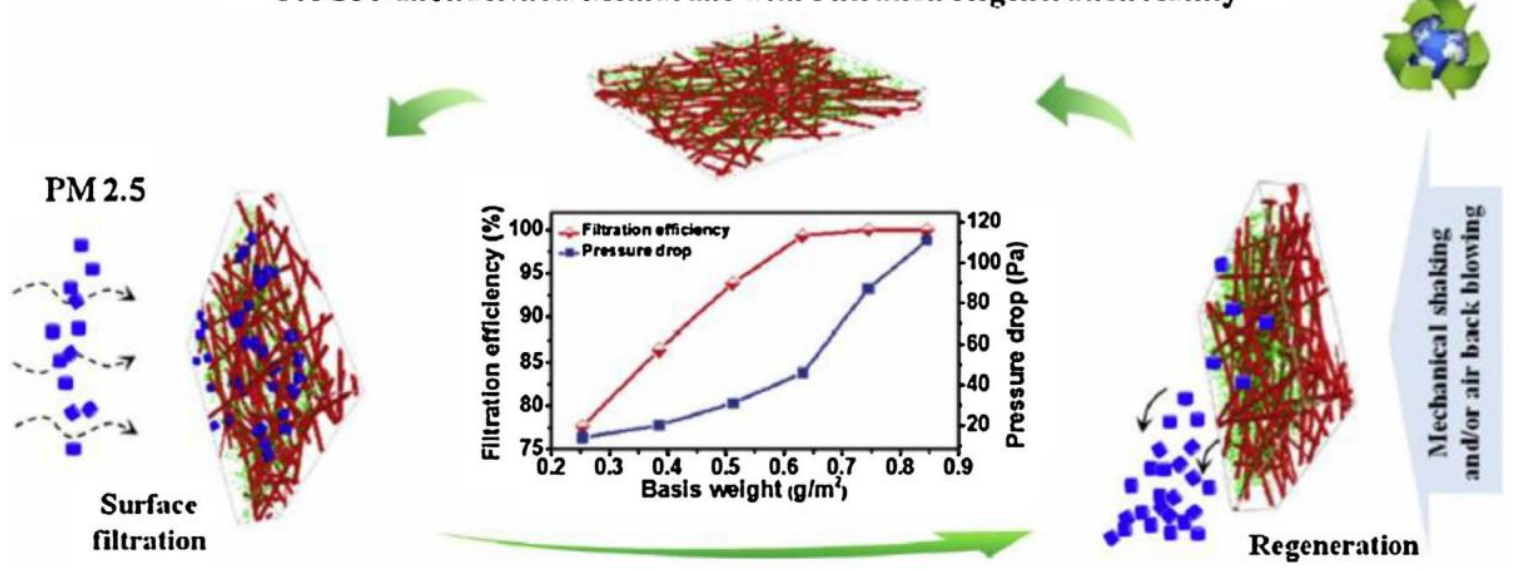

Fig. 8. PA-56 NFN membrane with filtration regeneration ability. Source from: Liu et al. (2015) 


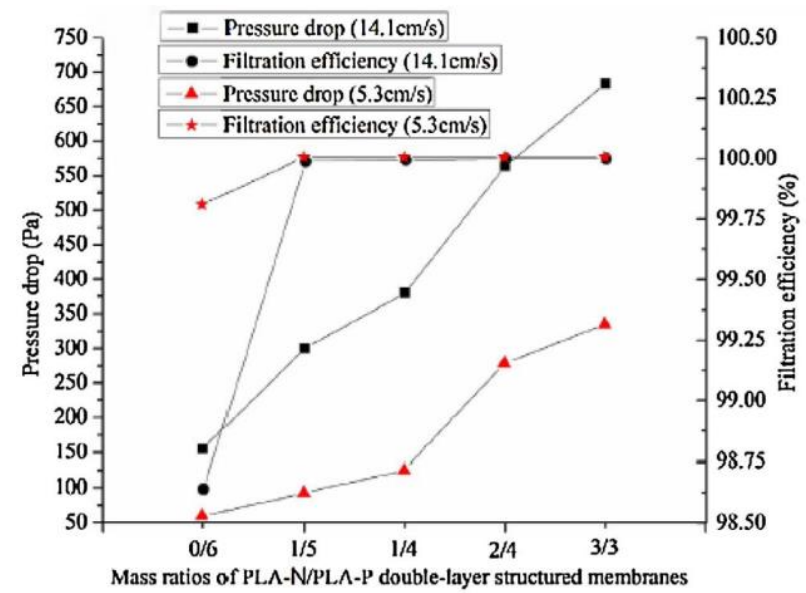

Fig. 9. Filtration properties of the PLA-N/PLA-P double-layer structured membranes with different mass ratios under face velocities of $14.1 \mathrm{~cm} / \mathrm{s}$ and $5.3 \mathrm{~cm} / \mathrm{s}$. Source from: Wang and Pan (2015)

\subsection{Energy assessment}

Air filters play a significant role in HVAC systems: they protect the equipment from dust and remove airborne pollutants. In HVAC systems, air filters are usually considered as commodity products as most of air filter products in the market offer similar performance. However, the latest developments in air filtration technology demonstrate that this is not always the case. Unfortunately, due to their commodity status, price became a crucial factor in choosing air filters. Apart from price, associate long-term energy costs should also be taken into consideration in filter selection.

According to Matela (2006), the operating costs of a standard pleated filter can achieve 10 times greater than its price. In the case of higher efficiency final filter the energy costs can be 4-5 times that its price. The total life-cycle cost consists of initial investment, maintenance, energy consumption and disposal costs. In general, operating costs accounts for $81 \%$ of the filter's total life-cycle cost, which is several times that of the initial investment and maintenance costs (18\%), while the disposal accounts only for1 percent of the total life- cycle cost. Considering the total life-cycle cost for a particular filter, a more energy-efficient filter may cost less, thus it can usually achieve energy conservation without any additional investment.

As Matela (2006) reported, the pressure drop of air filter greatly affects the annual energy consumption and cost. As shown in Fig. 10, apart from the initial pressure drop, the two types of filters are identical. The calculation process is given by Eq. (1) (Matela, 2006):

Energy consumption $=\frac{Q \times \Delta P \times t}{n \times 1000}$

$$
n \times 1000
$$

\begin{tabular}{|l|l|l|}
\hline & Filter A & Filter B \\
\hline Efficiency & MERV 14 & MERV 14 \\
\hline Filter style & $12^{n}$ Deep Rigid & $12^{n}$ Deep Rigid \\
\hline Media area & 120 sq. $\mathrm{ft}$. & 120 sq. $\mathrm{ft}$ \\
\hline Initial price & US\$70 & US\$70 \\
\hline Initial $\Delta \mathrm{P}$ & $0.45^{n}$ Water Gauge (WG) & $0.65^{n}$ Water Gauge \\
\hline Final $\Delta \mathrm{P}$ & $1.50^{n}$ WG & $1.50^{n}$ WG \\
\hline DHC & $300 \mathrm{~g}$ & $300 \mathrm{~g}$ \\
\hline Filter life & 12 months & 12 months \\
\hline Energy cost & US\$276/year & US\$305/year \\
\hline
\end{tabular}

Fig. 10. Specific parameters of two types of selected filters. Source from: Matela (2006). 
Filters are assumed to operate at $24 / 7 / 365$. The drive efficiency (n) of fan, motor, is $58 \%$, and the energy cost is US $\$ 0.08 / \mathrm{kWh}$. As lower initial and average pressure drop $(\Delta P)$ are provided by Filter $\mathrm{A}$, according to Eq. (1) it saves about $362.5 \mathrm{kWh}$ annually and therefore decreases the annual cost by US $\$ 29$ when compared to Filter B. It is important to note that a US\$29 annual cost saving is only for a single filter unit. Therefore, the cost saving would be extremely large for an entire HVAC (Heating, Ventilating and Air conditioning) system.

The energy consumed by HVAC systems accounts for $40 \%$ in commercial buildings in the US. The annually electricity bill of commercial buildings is about US\$65 billion, out of which US $\$ 26$ billion are consumed by the operation of HVAC systems. In addition, the HVAC system's total energy consumption which is affected by filter's pressure drop variation can be estimated via Eq. (1). For example, assuming that every filter's average pressure drop is $0.025^{\prime \prime}$ WG (from 0.700" WG to 0.675" WG), the total energy reduction is 12 billion kWh, which results in US\$960 million cost savings (Dave, 2006). Therefore, more energy could be conserved by reducing the resistance of filters, which is greatly influenced by the choice of the filtration material. New filtration materials, such as nanofibre and microglass membranes, have been developed to provide lower pressure drop and maintain high particle capture efficiency simultaneously. Routine maintenance, regular cleaning and foregoing prefiltering in the air filtration system can effectively prolong the service life of air filters life reduce both energy consumption and operational costs.

A model developed by Montgomery, Green, Rogak, and Bartlett (2012) to predict filter's energy efficiency and annual operation cost has been used to compare thirty different filters from six manufacturers. The results showed the particles concentration in the air stream and electricity cost place important role in the annual operation cost. Other parameters, such as the installation cost, filter purchasing price and the particle collection efficiency of filter, are less dominant. The total annual filter cost is a " $\mathrm{U}$ "-shaped curve with minimum at a particular operation (rather than over the filter's life as suggested by manufacturers), as shown in Fig. 11. Thus, the annual operational cost of a filtration system can be reduced if the filter can be changed once it reaches a resistance corresponding to the operation time of minimum annual cost. Detailed knowledge of the air handling system and installation are required to determine this resistance value as it will vary with system parameters.

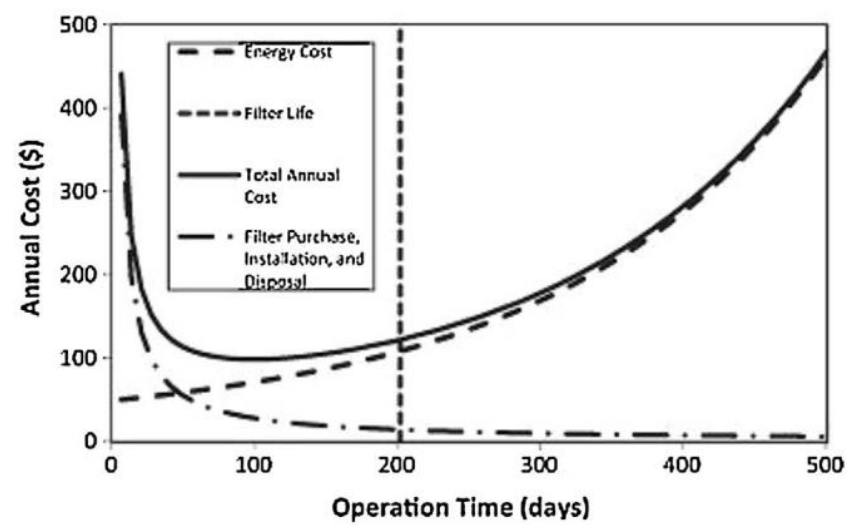

Fig. 11. Sample model result. Source from: Montgomery et al. (2012).

However, the air filters' pressure drop may have the totally opposite effect on the fan power of HVAC system with fan speed control. Zaatari, Novoselac, and Siegel (2014) field measured the units without fan speed control. They found that doubling the pressure drop leaded to $16 \%$ decrease of airflow, a median fan power reduction of $13 \%$ and the lowest influence on energy efficiency ratio (EER). In contrast, the same pressure drop increase for units equipped with fan speed control would increase the fan power with the same magnitude while other parameters remain unchanged. These results indicate the significance of air filter efficiency for achieving high indoor air quality and low energy consumption simultaneously.

For those systems that need not to consider the influence of pressure drop (such as electrostatic filters), using alternating voltage can reduce power consumption and achieve higher collection efficiency (Lin et al., 2011). Because the voltage on the electrostatic precipitators plates can be alternating, negative or positive, electrostatic precipitator system is highly tunable (Xu et al., 2013; Zhu et al., 2012). Trombe wall, according to Imbabi (2006), as an air filtration device, which realizes $10 \%$ energy reduction in space heating and cooling. The percentage can be further increased to approximately $30 \%$ with improvements such as integrating the breathing wall with effective air-to-air heat recovery equipment. Furthermore, Trombe wall simplifies the building air- handling system considerably, as it converts the external wall into a ventilation unit. This simple system reduces the application of controls, fans and pumps, which decrease the energy use by approximately $10 \%$. Bio-façade has various positive effects on building 
energy conservation, as it cools the air through evapotranspiration, increases wall insulation (in colder climates), façade shading (in hotter climates), and reduces the wind speed near the building. Shading from bio-façade reduces the temperature gradients of external walls and the hot conduction through opaque building envelope, also lowers the air infiltration into building, which leads to better building energy performance (Wood et al., 2014). Whole building energy simulation results from Wang and Zhang (2011) indicate that dynamic botanical air filtration system can replace $20 \%$ outdoor air supply without adversely effecting indoor air quality in Syracuse's climate. This could save $10-15 \%$ of annual energy consumption, which includes $1 \%$ saving in ventilation, $2 \%$ in cooling and $26 \%$ in heating. In addition, it was expected that higher percentage of energy consumption savings could be achieved in climate zones that need more energy for heating than Syracuse's climate. Further simulations should be conducted to research the applicability and energy saving potentials of DBAF for a wider range of different climatic and air quality conditions.

Table 15 summarizes the parameters of different domestic air filters/purifiers. All of the domestic air filters on the market integrate filtration technique with other air purification technologies, which produces an effect greater than the sum of its individual components. According to Table 15, rated power fluctuates from $2 \mathrm{~W}$ to $120 \mathrm{~W}$ along with different operational modes and purifier types. With assumed 24/ 7/365 operation, the annual energy consumption of domestic air purifiers can be calculated as follows:

$$
\text { Energy consumption }=\frac{\mathrm{P} \times \mathrm{T}}{1000}
$$

Where, $\mathrm{P}$ is the rated power $(\mathrm{W})$ and $\mathrm{T}$ is the time $(\mathrm{h})$. Then in this example, the annual energy consumption of domestic air purifiers varies from $122.64 \mathrm{kWh}$ to $7358.4 \mathrm{kWh}$.

Table 15 Specific parameters of different domestic air purifiers (Source from each Air filters' official website, 2017).

\begin{tabular}{|c|c|c|c|c|c|c|c|c|c|}
\hline Origin & Brand & Reference Model & $\begin{array}{l}\text { Applying } \\
\text { Space }\left(\mathrm{m}^{2}\right)\end{array}$ & $\begin{array}{l}\text { Rated } \\
\text { Power (W) }\end{array}$ & $\begin{array}{l}\text { Noise level } \\
\text { (dB) }\end{array}$ & $\begin{array}{l}\text { Clean Air Delivery } \\
\text { Rate (CADR) }\left(\mathrm{m}^{2} / \mathrm{h}\right)\end{array}$ & $\begin{array}{l}\text { Average Air- } \\
\text { flow rate }(\mathrm{m} / \mathrm{s})\end{array}$ & $\begin{array}{l}\text { HEPA Service } \\
\text { Life (Year) }\end{array}$ & $\begin{array}{l}\text { Average HEPA } \\
\text { Cost (CNY/year) }\end{array}$ \\
\hline \multirow[t]{9}{*}{ Europe } & \multirow[t]{3}{*}{ Philips } & AC4374 & $25-40$ & 56 & $35-65$ & $301-400$ & \multirow[t]{3}{*}{$3.1-6.8$} & \multirow[t]{3}{*}{1} & \multirow[t]{3}{*}{600} \\
\hline & & AC6608 & $50-85$ & 75 & $34 \sim 65$ & $400-710$ & & & \\
\hline & & AC8612 & 64-109 & 105 & $34-68$ & $400-910$ & & & \\
\hline & \multirow[t]{3}{*}{ Blueair } & 303 & $17-30$ & $13-60$ & $34.7-55.9$ & 105-205 & \multirow[t]{3}{*}{$1.3-4.6$} & \multirow[t]{3}{*}{$0.5-1$} & \multirow[t]{3}{*}{296} \\
\hline & & $450 \mathrm{E}$ & $31-50$ & $30-80$ & $32-52$ & $401-500$ & & & \\
\hline & & Pro XL & $56-96$ & $30-120$ & $39.5-64$ & $>800$ & & & \\
\hline & \multirow[t]{3}{*}{ Electrolux } & EAC103 & $30-39$ & 150 & $28.5-43.3$ & 193.5 & \multirow[t]{3}{*}{$1.7-7.2$} & \multirow[t]{3}{*}{$1-1.5$} & \multirow[t]{3}{*}{329} \\
\hline & & EAC403 & $40-59$ & 150 & $27-60$ & 579 & & & \\
\hline & & CN500AZ & $40-59$ & 125 & $28-51$ & 439 & & & \\
\hline \multirow[t]{9}{*}{ Japan } & \multirow[t]{3}{*}{ Sharp } & FU-GFM50-B & 30 & 55 & 65 & 312 & \multirow[t]{3}{*}{$3.1-6.3$} & \multirow[t]{3}{*}{$5-10$} & \multirow[t]{3}{*}{122} \\
\hline & & FX-CF100-N & 80 & $8-118$ & $38-68$ & 800 & & & \\
\hline & & KI-BB60-W & 37 & 62 & 62 & 369 & & & \\
\hline & \multirow[t]{3}{*}{ Panasonic } & F-VXG70C-N & $25-44$ & $10-50$ & $20-50$ & 368 & \multirow[t]{3}{*}{$1.6-5.8$} & \multirow[t]{3}{*}{1} & \multirow[t]{3}{*}{240} \\
\hline & & F-VJL55C & $31-52$ & $10-53$ & $22-53$ & 322 & & & \\
\hline & & F-VJL90C & $>100$ & $11-88$ & $23-55$ & $501-700$ & & & \\
\hline & \multirow[t]{3}{*}{ Daikin } & MCK38RV2C-N & $21-30$ & $9-32$ & $34-60$ & $200-228$ & \multirow[t]{3}{*}{$0.8-8.3$} & \multirow[t]{3}{*}{2} & \multirow[t]{3}{*}{199} \\
\hline & & TCK70P-T & 50 & $12-75$ & $23-54$ & $401-500$ & & & \\
\hline & & MCK57LMV2 & $21-34$ & $8-39$ & $31-60$ & $270-342$ & & & \\
\hline the United & Honeywell & KJ300F-PAC1101G & $21-36$ & $7.5-55$ & 65 & 305 & $3.3-6.1$ & $0.5-1$ & 219 \\
\hline States & & KJ450F-JAC2022S & $31-54$ & $2-66$ & 67.1 & $401-500$ & & & \\
\hline & & KJ700F-PAC2127W & $49-84$ & 72 & 69 & $243-700$ & & & \\
\hline China & Yadu & KJ500G-S5 & $35-60$ & 80 & $\leq 65$ & 577 & $1.2-6$ & $0.5-1$ & 329 \\
\hline & & KJG3066DR & $>60$ & 60 & $\leq 48$ & $>360$ & & & \\
\hline & & KJG588G-P5 & $80-100$ & 80 & $\leq 65$ & 588 & & 1 & \\
\hline & Broad & TA240 & $12-20$ & $10-30$ & $20-45$ & 240 & - & 0.25 & 198 \\
\hline & & TA1000 & $41-60$ & $13-40$ & $25-45$ & 1000 & & & \\
\hline & & TA2000 & $>61$ & $30-110$ & $30-53$ & 2000 & & & \\
\hline & Lexy & KJ703-F & $51-99$ & 55 & 32 & $100-550$ & $3.4-8.1$ & $0.5-1$ & 249 \\
\hline & & KJ601 & $51-99$ & 60 & 66 & $301-400$ & & & \\
\hline & & KJ801 & $60-100$ & 60 & 66 & $480-840$ & & & \\
\hline & TCL & TKJ300F-S102 & $10-60$ & 68 & $17-35$ & 300 & $3.2-7.2$ & 1 & 288 \\
\hline & & F220B & $30-60$ & 45 & $\leq 35$ & 220 & & & \\
\hline & & TKJ400A5 & $40-60$ & 45 & $20-40$ & 403 & & & \\
\hline South Korea & Samsung & AX022FCVAUW/SC & $\leq 30$ & 10.8 & $30-40$ & 179 & $2.2-5.4$ & 2 & 300 \\
\hline & & KJ393G-K5050WD & 47 & 45 & $\leq 61$ & 393 & & & \\
\hline & & KJ720F-K7586WF & $50-86$ & 100 & $29-67$ & 719 & & & \\
\hline
\end{tabular}




\subsection{Thermal comfort}

With regards to thermal comfort, the most commonly reminded indicator is air temperature. However, air temperature alone is not enough to accurately describe thermal comfort, as other personal and environmental factors should be considered as well. Air velocity is a significant factor in indoor thermal comfort. For example, a stagnant heated indoor environment would cause people to feel stuffy. Table 15 shows that the average air velocity of domestic air purifiers varies greatly and ranges from about $0.8 \mathrm{~m} / \mathrm{s}$ to $8.3 \mathrm{~m} / \mathrm{s}$. However, outlet air velocity is generally neglected not only by consumers, but also by retailers. The Chinese brand 'Broad' don't even mention air flow rate in their product specifications. When facing the outlets of air filters, they produce strong, non-uniform air velocity fields, which result in draught sensations and non-uniform skin heat losses.

Air movement can result in sensation of coldness and local discomfort, particularly when unclothed body parts are exposed to various air speeds. Under these circumstances, higher temperatures feel more comfortable than the Predicted Mean Vote (PMV) model would predict. For example, according to ANSI/ASHRAE Standard 55-2013 (Ashrae, 2014), air movement increases the maximum temperature for an office space from $27.5^{\circ} \mathrm{C}$ to $30{ }^{\circ} \mathrm{C}$ in the summer when the speed is elevated from $0.8 \mathrm{~m} / \mathrm{s}$ to $1.2 \mathrm{~m} / \mathrm{s}$. Thus, the outlet air velocity should be adequate, and a uniform wind field can effectively reduce draft sensation and maintain thermal comfort. Compared to a domestic air filter, the wind field of central air-conditioning is smoother near the public activity areas. It is mainly because air inlets and outlets in the case of central air-conditioning are generally located at the corners of the room to achieve regular air circulation, as shown in Fig. 12.

However, air velocity is not the only parameter to influencing thermal comfort. Fresh clean air, which is essential for sustainable indoor environment, must be distributed in occupants' breathing-zones evenly. While there is a fresh air requirement for HVAC systems, domestic air filters have no such requirements. For example, the Chinese General Administration of Quality Supervision (2003) stipulated minimum fresh air ventilation rate requirements for different buildings (see Table 16). Domestic air filters only purify the indoor air inside a filtration system and then discharged it without the introduction of any fresh air. Therefore, the indoor air quality should be monitored and the air pollution level of spaces should be available to the public. Because human activities has a major impact on indoor air quality (EPAH, 1991), for achieving sustainable indoor environments, it is suggested that people should wear sensors that can record pollution levels. The data collected this was could be of use to facilities managers and local authorities as could obtain more detailed knowledge of the intensity and distribution of indoor air pollution.

While outlet air temperature, relative humidity and some other parameters are taken into consideration in the design of an HVAC system, domestic air filtration industry gives much less consideration to these aspects. According to Chinese Code for design of heating ventilation and air conditioning (General Administration of Quality Supervision, 2003), to ensure indoor thermal comfort, outlet air velocity, air temperature and relative humidity requirements are the function of room use and season. Taken summer indoor design conditions of comfort air conditioning as an example, all of these design conditions have explicit stipulations. In contrast, the attention of Chinese National Standard of "Air Cleaners" (China National Standardization Management Committee and General Administration of Quality Supervision, 2008) mainly focuses on air cleaners' type, technical requirements, experimental methods and inspection regulations etc., and barely considers the air cleaners' influence on thermal comfort. The parameters including air temperature and relative humidity are not mentioned neither in the National Standard, nor in the manufacturers' instructions. Also, the outlet air velocity is much higher than prescribed by the standards of the national HVAC code. The 'outlet air velocity' in Table 17 summarizes the different requirements detailed in Table 15 (obtained from different air cleaner manufacturers).

Water washing purification technique is usually applied in air purifiers, which would influence the indoor air humidity. The humidity is one of the physical parameters affect human thermal comfort, it has little influence on human thermal comfort when temperature, wind speed and the average radiation temperature remain in a comfortable range. The recommended indoor humidity range for air conditioned space is between $30 \%$ and $60 \%$ (Wolkoff and Kjærgaard, 2007). Humans feel uncomfortable when humidity levels are higher than 60\%. When reducing humidity, it can make the person feels cool, dry, comfortable. Despite these effects, research on the influence of domestic air purifier on indoor air humidity seems to be a neglected subject. Pérez-Urrestarazu et al. (2016) conducted a study on indoor Active Living Wall (ALW) at the University of Seville in Spain. Preliminary results showed that $0.8-4.8^{\circ} \mathrm{C}$ temperature drops were achieved at different distances from the ALWs. When the initial conditions in the room were drier and warmer, the cooling process was more efficient. The research of Wang and Zhang (2011) indicated that a dynamic botanical air filtration system (DBAF) would cause $9-13 \%$ relative humidity 
increase and $1{ }^{\circ} \mathrm{C}$ temperature decrease in the chamber air after its operation. Under office circumstance the operation of DBAF would lead to $17.7 \%$ relative humidity increase and $0.5^{\circ} \mathrm{C}$ temperature decrease. This moisture generation enhances winter's thermal comfort condition, while its effect on thermal comfort and cooling is negligible in the summer.

Table 16 Ventilation rate of fresh air requirement (Adapted from Chinese Code for design of heating ventilation and air conditioning).

\begin{tabular}{|c|c|c|c|c|c|c|c|c|c|c|}
\hline \multirow[t]{2}{*}{ Room Type } & \multicolumn{5}{|c|}{ Non-smoking } & \multicolumn{3}{|c|}{ Smoked Lightly } & \multicolumn{2}{|c|}{ Smoked Heavily } \\
\hline & $\begin{array}{l}\text { Apartment } \\
\text { Nilla }\end{array}$ & Shopping mall & Computer room & Gymnasium & Sickroom & $\begin{array}{l}\text { Apartment } \\
\text { Villa }\end{array}$ & Office & Dining room & $\begin{array}{l}\text { KTV/ } \\
\text { Bar/hotel }\end{array}$ & Conference room \\
\hline Air exchange per hour & $0.4-0.7$ & $1.6-3.9$ & $1.1-2.7$ & $2.5-6.3$ & $0.5-1.3$ & $0.5-1.0$ & $1.1-2.7$ & $1.3-3.1$ & $1.9-4.7$ & $2.1-7.8$ \\
\hline
\end{tabular}

Table 17 Comparison of comfort air conditioning and domestic air filter's indoor design conditions (Summer).

\begin{tabular}{lll}
\hline Parameters & \multicolumn{1}{l}{ Type } \\
\cline { 2 - 3 } & HVAC system & Domestic air cleaners \\
\hline Air temperature & $24-28^{\circ} \mathrm{C}$ & - \\
Outlet air velocity & $<0.3 \mathrm{~m} / \mathrm{s}$ & $0.8 \mathrm{~m} / \mathrm{s}-8.3 \mathrm{~m} / \mathrm{s}$ \\
Relative humidity & $40-65 \%$ & - \\
\hline
\end{tabular}

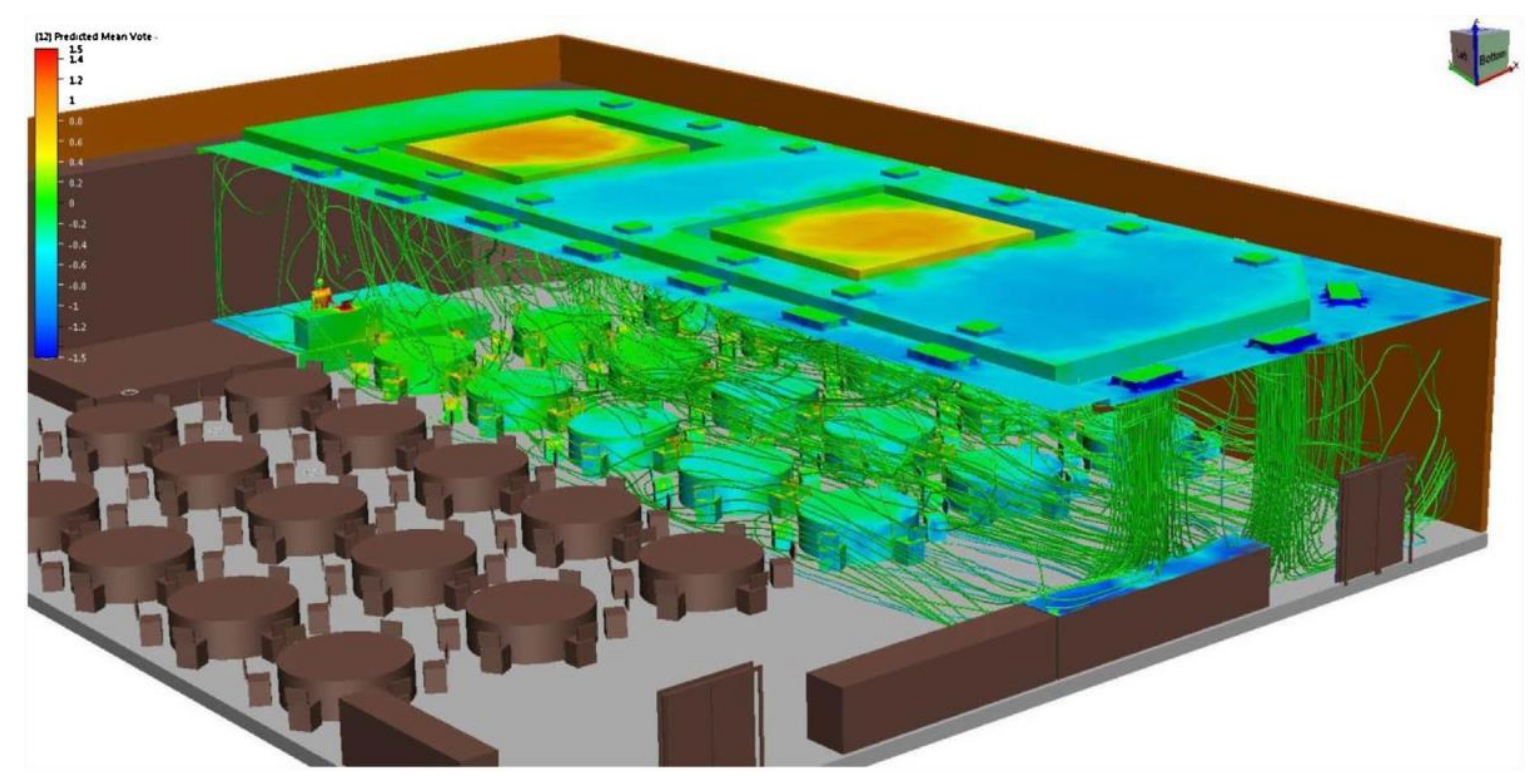

Fig. 12. Overall air velocity fields of central air-conditioning. Source from Hartog (2013).

\subsection{Acoustic impact}

Noise levels are generally divided into four categories, as shown in Fig. 13. Noise can be detrimental to human health, which is indicated by its three types of effects. Physical effects may influence the health of people adversely and directly, such as resulting in hearing loss or in the vibration of bodily components. The second type is the physiological effect, which is associated with bodily reasons such as a general stress response or heightened blood pressure. The last type is also a psychological effect that affects the welfare of people rather than their body wellbeing. Annoyance, complaints and distractions are some of the examples to these effects (Passchier-Vermeer and Passchier, 2000). Because of the adverse effects of noise, many governments have established standards to control the 
levels of machine noise. According to the Chinese National Standard as shown in Table 18, when CADR (Clean Air Delivery Rate) is equal or lesser than $150 \mathrm{~m}^{3} / \mathrm{h}$, the machine noise should be equal or lesser than $55 \mathrm{~dB}$; when the CADR is greater than $150 \mathrm{~m}^{3} / \mathrm{h}$ and less than $300 \mathrm{~m}^{3} / \mathrm{h}$, the machine noise should be equal or lesser than $61 \mathrm{~dB}$; when the CADR is greater than $300 \mathrm{~m}^{3} / \mathrm{h}$ and less than $450 \mathrm{~m}^{3} / \mathrm{h}$, the machine noise should be equal or lesser than $65 \mathrm{~dB}$; when the CADR is greater than $450 \mathrm{~m}^{3} / \mathrm{h}$, the machine noise should be equal or lesser than $70 \mathrm{~dB}$. As Table 15 shows, the noise of domestic air filters varies from $17 \mathrm{~dB}$ to $70 \mathrm{~dB}$. Combining their CADR and noise level, all the air filtration products on the market are conforming to the requirements of National Standard.

Nevertheless, there is a lack of international noise standard as different countries or even cities adopt different noise standards. Table 19 illustrates the noise standards of San Juan city. It differs from that of Chinese cities as it introduces different levels to different time periods. Nevertheless, the maximum limits of both standards are similar.

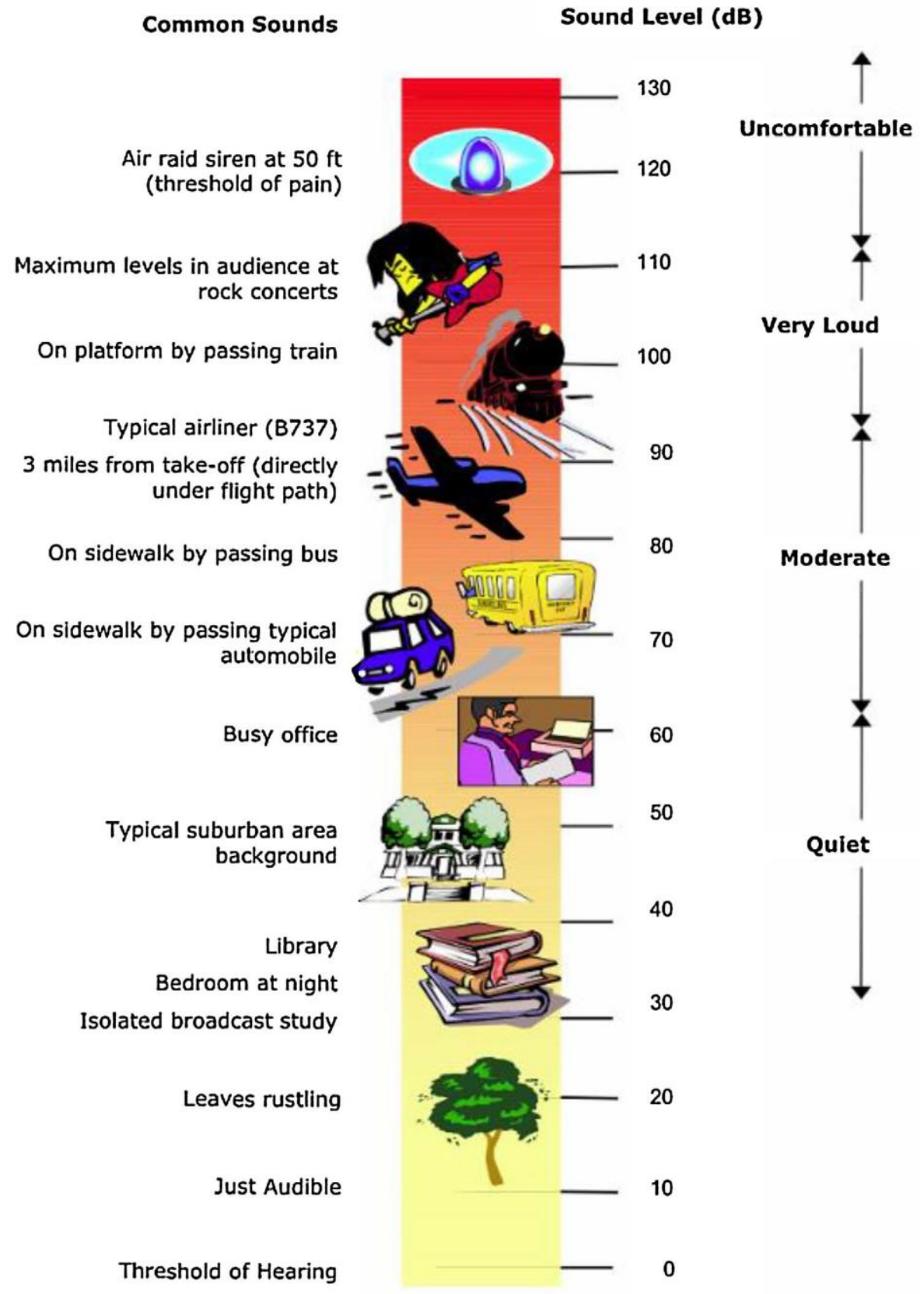

Fig. 13. Acoustic level. Source from: Cowan and James (1994). 
Table 18 Chinese Noise Standards for Residential and Public and Institutional Districts.

\begin{tabular}{ll}
\hline CADR of air filters & Noise Level $(\mathrm{dB})$ \\
\hline$<150 \mathrm{~m}^{3} / \mathrm{h}$ & $<55$ \\
$150 \mathrm{~m}^{3} / \mathrm{h}-300 \mathrm{~m}^{3} / \mathrm{h}$ & $<61$ \\
$300 \mathrm{~m}^{3} / \mathrm{h}-450 \mathrm{~m}^{3} / \mathrm{h}$ & $<65$ \\
$>450 \mathrm{~m}^{3} / \mathrm{h}$ & $<70$ \\
\hline
\end{tabular}

Table 19 Exterior Noise Standards for Residential, Public and Institutional Districts (Adapted from: San Juan Capistrano Municipal Code (2013))

\begin{tabular}{ll}
\hline Noise Level & Time Period \\
\hline $65 \mathrm{~dB}(\mathrm{~A})$ & 7:00 a.m.-7:00 p.m. \\
$55 \mathrm{~dB}(\mathrm{~A})$ & 7:00 p.m.-10:00 p.m. \\
$45 \mathrm{~dB}(\mathrm{~A})$ & 10:00 p.m.-7:00 a.m. \\
\hline
\end{tabular}

\subsection{Maintenance and economic assessment}

The maintenance of filters is often neglected both during the research process and over a system's operation period. Filters need to be replaced or cleaned regularly, otherwise they might be become secondary sources of pollution. The longer time the filter works, the greater the possibility of a potential pollution. Consequently, warnings systems need to be integrated into building management system (BMS) when filtration system is applied. According to different domestic air filters' official website, the majority of the products on the market integrate warning systems with filtration systems in order to prompt the public when filters need to be replaced.

Although the high efficiency of HEPA filter made it an industry standard, it also has a high maintenance cost as the filter needs to be changed on a yearly basis. HEPA is characterized by a large pressure fall, which with continual use would grow and increase the operational cost (Novick, Monson, \& Ellison, 1992). According to Table 15, the lifetime of different brands of HEPA filters are limited to 0.5 year to 1 year and all of them has high replace costs. Only one type of HEPA filter, among the 12 can maintain high filtration efficiency over 5-10 years of continued use. Similarly, the main disadvantage of using nanofibre mats is their costs. The production process of nanofibre mats is non-trivial, which includes the use of special facilities. Furthermore, nanofibre mats also need to be replaced frequently and their long-term (months-long) performance and durability seem to lack detailed research (Brincat et al., 2016).

Compared to conventional HEAP filters, Trombe wall provides alarge area to filtration, which reduces flow velocity by a factor of 100 or even more. This method enhances energy efficiency with the recovery from relatively sparse fibrous insulation material to a highly effective air filtration device, significantly reduced the plant requirement of size, complexity and cost. In addition, it realizes a lifetime of air filtration with no added cost, while achieves the benefits of air supply distribution (Imbabi, 2006). With regards to cost, ESPs has a higher initial setup costs than physical filters, but do not need to be replaced yearly. Their additional cost is expected to be less than that of physical filters associated with much smaller pressure drop. Also, while the installation cost of cold plasma air filtration is rather high, but the filter only needs regular cleaning rather than replacement, and the pressure drop is negligible. The operating cost is higher than that of ESPs (Brincat et al., 2016).

UV-PCO has high capital and operational costs. The capital costs are associated with the configuration of UV-PCO reactor designed, involving catalyst type and property, substrate type and format, also includes the amount of UV lights. Zhong and Haghighat (2015b) listed the most popular PCO air filters available in the market and compared their physical properties and prices. The results showed carbon cloth-supported PCO filter to be lowest in unit price with highest BET specific surface area, which makes it good candidate for PCO air cleaners. However, its texture produces the highest pressure drop that increases in the energy consumption of the HVAC fan. The pressure drop can be significantly reduced by integrating photocatalysts with honeycombshape substrate, but in reverse sacrifice PCO performance due to catalyst surfaces would contact portion of contaminated air. 


\section{Further research directions}

\subsection{Trombe wall}

The Trombe wall made up of breathing wall panels not only filters air, but also acts as heat recovery system. Its latter function leads to decreased energy requirements for space heating and cooling. Specifically, Trombe wall provides a higher ventilation level for building associated with a large reaction area, hence improves indoor air quality and reduces energy consumption. A more synergetic link would be created between the building and its surrounding by associating HVAC system with building fabric. With the application of breathing wall, the indoor exhausted air would also be filtered before it discharged to the outdoor. This means that a breathing building has the ability to clean the local environment. With successfully deployed, it holds the promise of a new type of energy efficient 'breathing' building and reverses the age-old trend of buildings as environmental polluters. Also, it provides significant benefits to residents, as it paves the way for self-cleaning urban environments and helps combat global pollution.

\subsection{Botanical biofiltration}

Botanical biofiltration is proved effective with different types of VOCs. However, studies on indoor air biofiltration techniques are still rather limited, even though biotechnology made great progress over the past ten years. The majority of research demonstrates the lack of studies on the influence of phytoremediation factors and their process performance, such as the plants' quantity and categories, microorganism types, pollutant composition and light source (Soreanu et al., 2013). The effectiveness of phytoremediation systems can be depressed by the competition between microorganisms and plants under limited nutrient resources circumstance. According to Mallany, Darlington, and Dixon (2000), this similar competition was discovered in botanical biofilters through preliminary observation, which provides an interesting research direction for the future.

To date, botanical filters have not been widely adopted in the built environment. The spaces occupied by botanical filtration systems can be very diverse in terms of architectural composition and pollutant loads. Elimination of volatile organic chemicals is the most obvious function of biofilters. Other areas of their application include such as $\mathrm{CO} 2$ control, humidity control and spore loads management need further investigations. The impact of botanical filtration technique on the building energy performance is a critical problem that also influences the occupants' acceptance. In addition, system maintenance also needs to be taken into consideration.

\subsection{Energy label}

The energy labeling of household appliances was proposed several years ago in the European Union and not only has achieved good success but also has been accepted by different interested parties. As shown in Fig. 14. Energy labels should be uniform if it is planning to extend to all or most domestic electric appliances, such as airconditioning, ventilation, air filtration and heating equipment. However, it should be admitted that finding a straightforward indicator to rate the energy performance of air filters is not easy, and the application of the "energy efficiency" concept to air filtration and cleaning devices is a fairly recent notion.

Actually "filtration efficiency" has been adopted for many years, while it only referred to the pollution removal capacity of a filter, which is the fraction of pollutants that are filtered over a given time. While the operation of air purifying devices is one of the major causes of energy consumption, the use of "efficiency" without a modifier generally refers to pollutant-removal efficiency only. Despite their effect on energy consumption, no energy rating system has been established for air filters. According to Tronville (2009), interested parties are paying increasing attention to energy efficiency, it will drive the filter industry to consider this new concern. In order to establish an energy rating systems, several challenges remain to be overcome. If existing energy rating and labelling system, the energy consumption of air filters can be judged and hence can indicate the best choice of different options (filter A costs $\mathrm{X}$ more than filter $\mathrm{B}$ but allows $\mathrm{Y}$ savings) by comparing the overall cost (money or life-cycle $\mathrm{CO} 2$ emissions). However, energy labelling and rating system could be of little use without an effective simulation method. 


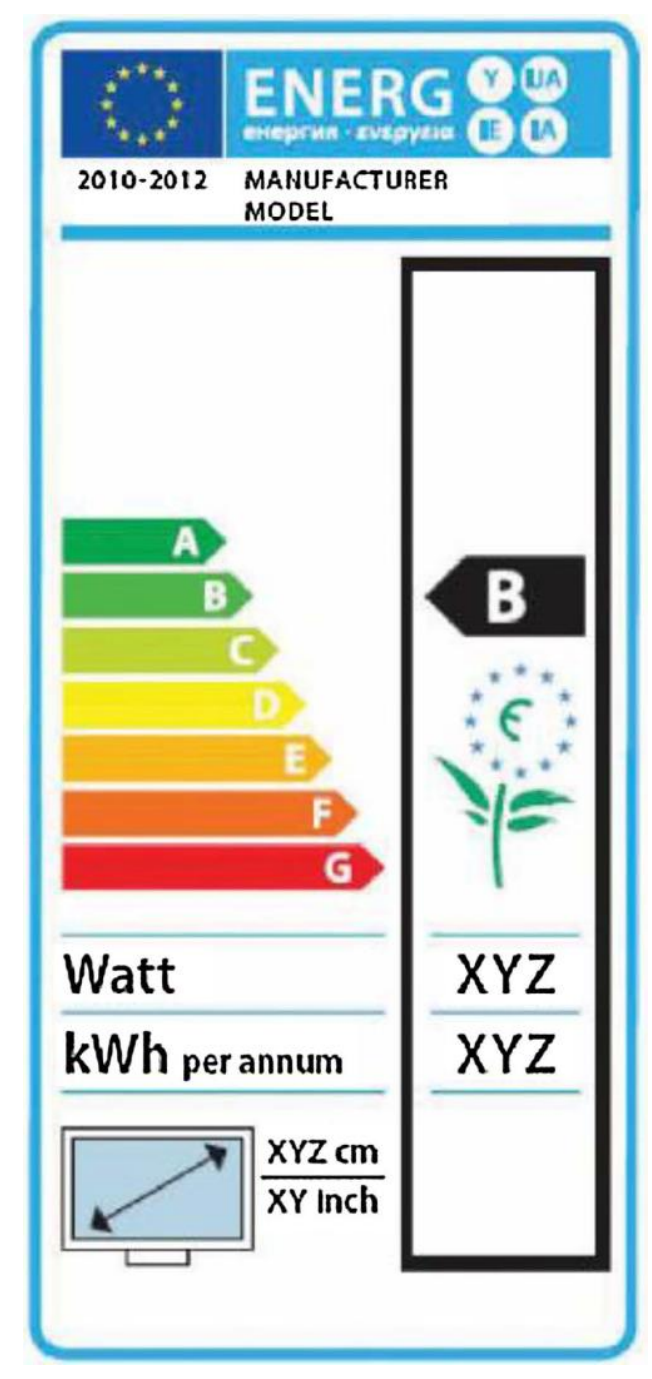

Fig. 14. The familiar energy label for household. Source from: Tronville (2009).

\subsection{Simulation method}

It should be noted that bench tests would probably never be able to reproduce what happens during the operation of an air filter accurately. This problem has not attracted much attention in the past as the research and development predominantly focused on testing which filter is more effective under identical circumstances. Additionally, as the energy label could possibly probably be of little use without the effective simulation method, bench tests and the aerosol used to age the filters in laboratory need to be optimized to develop better tools for future energy rating systems (Tronville, 2009). The market provides a strong pressure to establish and standardise a numerical simulation approach. Hanley and Owen (2003) developed a new loading dust that focus to reproduce the drop off in efficiency affecting certain types of filters. And some other studies were conducted in progress by research institutes in Europe and USA. To developed a better simulation method for air filters needs supports and strong actions from all interested parties.

\subsection{Integrating air filtration technologies with building information modelling (BIM) platforms}

With the development of information technology, BIM platforms have attracted the attention of various fields and stakeholders. BIM have the advantage of carrying attributes for selecting and ordering each model element automatically, providing cost estimates, as well as tracking and ordering materials. Integrating air filtration technology into BIM could enrich its functionality. BIM platform could build and show air filtration systems by adapting air filtration data family, make the system visual and easy to understand. BIMs could integrate energy 
simulation and air quality monitoring, and thus could make predictions for indoor environmental quality and energy consumption. As BIM platforms lack data family about air filtering products, the first step would be to build an air filtration technique database. According to earlier explorations into this topic, there are very few review papers on air filtration techniques and no research was found on air filtration technologies database, let alone on combining their use with BIM platforms. Integrating air filtration technologies with BIM platform is undoubtedly a research topic for the future, along with realizing better indoor environment monitoring and prediction.

\section{Conclusions}

Sustainable and healthy indoor environments have received much attention over the year. Studies, aiming to reduce or remove possible sources of indoor air contaminants from consumer goods and building products, have effectively halted the deterioration of indoor air quality. Currently, a large variety of air filters technologies are available for removing indoor air pollutants, the review of which are summarized below.

Traditional fibrous filters have numerous advantages, such as high removal efficiency, low initial cost and simple structure. However, they are also characterized by high pressure drop, high maintain costs and filter colonization. In order to overcome the latter, traditional physical filters need to be coated by chemicals or nanoparticles to exhibit fungicidal or fungistatic properties. In addition, single filtration techniques are ineffective when multiple types of pollutants are present. Thus, the strategic combination of filtration technique with other purification technologies is necessary to improve their performance via the synergistic effect.

Electrostatic air filter is theoretically considered as permanent and the filtration efficiency of the particles can achieve $82 \%$ to $94 \%$. Cold plasma (or non-thermal plasma) air filtration is effective in the case of fungal spores and airborne bacteria, and can achieve 85\%-98\% decontamination even with low exposure time (0.06 s). The Trombe wall system constructed of breathing wall panels can achieve high filtration efficiency $(99.4 \%)$ in the case of PM10 and at extremely low blocking rate (with 60 years of service life), even in polluted urban environments. Biofiltration technique is recognized as 'most easily adapted to mechanically ventilated building or on the pit fans of naturally ventilated buildings'. Their utilization in building air filtration is continuously increasing.

The filtration efficiency of general fibrous filters is directly proportional to the air pressure drop. High pressure drop implies additional energy consumption and increased operating cost. In this sense, nanofibre has an advantage as it combines high air filtration efficiency and low pressure drop. However, its biggest disadvantage is its high initial cost. Compared with fibrous filters, high pressure drop is avoidable by electrostatic air filters and biofiltration systems. Dynamic botanical air filtration systems can reduce $20 \%$ of outdoor air supply without adversely affecting indoor air quality, which in the case of Syracuse climate could save 10-15\% of annual energy consumption.

According to recent studies, most research in the subject focuses on air filter efficiency improvements, pressure drop reduction, operational costs savings, etc., while the thermal comfort and acoustic effects of air filtration are generally ignored. Regulations guiding HVAC system design generally focus on outlet air velocity, outlet air temperature, relative humidity and other related parameters. Whereas domestic air filtration standards are primarily concerned with air cleaner types, technical requirements, experimental methods and inspection regulation, etc., and seldom consider the influence of air purification on thermal comfort. Due to the lack of an international noise standard, allowed noises levels may different from country to country, and sometimes even by cities.

Additionally, the indoor air quality monitoring needs more attention and the air pollution levels of monitored spaces should be available to the public. Since indoor air quality is most influenced by human activities, it is suggested that people wear pollution sensors. The data collected this way could be useful to facilities managers and local authorities who therefore could gain a more precise knowledge on the extent and distribution of indoor air pollution. Furthermore, there is an emerging need for developing energy rating systems and simulation methods for air filters.

To conclude, emerging filtration technologies such as nanofibre, Trombe wall and botanical biofiltration are likely to become more prevalent over the coming years globally. The integration of air filtration technologies with BIM platforms is a possible avenue of future research along with expanding indoor environment monitoring and improving air quality predictions. This paper provided guidance for future air filtration technology research and development in order to achieve sustainable and healthy building ventilation.

\section{Acknowledgements}

The authors would like to acknowledge their sincere appreciation for the financial support from Ningbo Enrich People Project of China (Grant No. 2016C10035) and the IDIC (International Doctoral Innovation Centre) program of the University of Nottingham (China campus). 


\section{References}

Aghighi, A., \& Haghighat, F. (2015). Evaluation of nano-titanium dioxide (TiO2) catalysts for ultraviolet photocatalytic oxidation air cleaning devices. Journal of Environmental Chemical Engineering, 3, 1622-1629.

Aghighi, A., Haghighat, F., Zhong, L., \& Lee, C.-S. (2014). Evaluation of ultraviolet-photocatalytic oxidation of light alcohols at sub-parts per million concentrations. Science and Technology for the Built Environment, 21, 160171.

Ahn, Y., Park, S., Kim, G., Hwang, Y., Lee, C., Shin, H., et al. (2006). Development of high efficiency nanofilters made of nanofibers. Current Applied Physics, 6, 1030-1035.

AIR-CARE (2016). Electrostatic air filters [Online]. Available: https:/ / www.air-care.com/ electrostatic-airfilters / [Accessed 28 June 2016].

Aly Hassan, A., \& Sorial, G. A. (2011). Treatment of dynamic mixture of hexane and benzene vapors in a Trickle Bed Air Biofilter integrated with cyclic adsorption/ desorption beds. Chemosphere, 82, 521-528.

Amos, J. (2016). Polluted air causes 5.5 million deaths a year new research says. BBC News. Air filters' official website, 2017, http://www.philips.com/global, https:/ / www.

blueairweb.com/, www.electrolux.com/, www.sharp-world.com/, www.panasonic.

com/global/home.html, www.daikin.com/, www.honeywell.com/, http:/ /www. yadu.com.cn/, http:/ / www.lexy.cn/, www.tcl.com/, http:/ / www.samsung.com/ cn 2017; [Accessed 28 June 2016].

Arsenault, P. J., Faia, Ncarb, Leed AP, \& Darlington, A. (2012). Indoor Air Biofilters Deliver Clean Air Naturally, Biological systems function to improve air quality while providing beautiful form [Online]. Continuing Education Center. Available: https:// continuingeducation.bnpmedia.com/course.php?L=326\&C=951\&P=1 [Accessed 30 June 2016].

Ashrae \& The American National Standards INSTITUTE (2014). Thermal Environmental Conditions for Human Occupancy. ANSI/ ASHRAE Addendum b to ANSI/ ASHRAE Standard 55-2013.

Aussawasathien, D., Teerawattananon, C., \& Vongachariya, A. (2008). Separation of micron to sub-micron particles from water: Electrospun nylon-6 nanofibrous membranes as pre-filters. Journal of Membrane Science, 315, 11-19.

Australian Government (2003). Air quality standards [Online]. Department of the environment Available: http:/ / www.environment.gov.au/protection/air-quality/air- quality-standards [Accessed May 15, 2016].

Bahri, M., \& Haghighat, F. (2014). Plasma-based indoor air cleaning technologies: State of the Art Review. CLEAN-Soil Air Water, 42, 1667-1680.

Bahri, M., Haghighat, F., Rohani, S., \& Kazemian, H. (2016). Impact of design parameters on the performance of non-thermal plasma air purification system. Chemical Engineering Journal, 302, 204-212.

Bandosz, T. J., \& Ania, C. O. (2006). Other forms of carbon absobents. In T. J. Bandosz (Ed.), Activated carbon surfaces in environmental remediation.

Baumgartner, H. P., \& Loffler, F. (1986). The collection performance of electret filters in the particle size range $10 \mathrm{~nm}-10 \mathrm{~mm}$. Journal of Aerosol Science, 17, 438-445.

Brincat, J. P., Sardella, D., Muscat, A., Decelis, S., Grima, J. N., Valdramidis, V., et al. (2016). A review of the state-of-the-art in air filtration technologies as may be applied to cold storage warehouses. Trends in Food Science \& Technology, 50, 175-185.

Brown, R. C., Gray, W. R., Blackford, D. B., \& Bostock, G. J. (1988). Effect of industrial aerosols on the performance of electrically charged filter material. Annals of Occupational Hygiene, 32, 271-294.

Cai, Z., \& Sorial, G. A. (2009). Treatment of dynamic VOC mixture in a trickling-bed air biofilter integrated with cyclic adsorption/desorption beds. Chemical Engineering Journal, 151, 105-112.

City Of Sanjuan Capistrano (2013). San juan capistrano municipal code. Noise standards (residential and nonresidential). Seattle, Washington: Quality Code Publishing.

China National Standardization Management Committee and General Administration of Quality Supervision, 2008. Chinese National Standards Air Cleaner. China.

Chuaybamroong, P., Chotigawin, R., Supothina, S., Sribenjalux, P., Larpkiattaworn, S., \& Wu, C. Y. (2010). Efficacy of photocatalytic HEPA filter on microorganism removal. Indoor Air, 20, 246-254.

Colbeck, I., \& Lazaridis, M. (2013). Filtration Mechanisms. Aerosol science: Technology and applications. Chichester, UK: Wiley.

Comité Européen De Normalisation (2012). EN779: 2012 and energy efficiency classification [Online]. 
Available: http:/ / www.aafeurope.com/_uploads/file/21-02- 2014\%20aaf\%20leaflet\%20en7792012\%20+\%20 [Accessed 15 May 2016].

Corning, P. (2003). Conjuring human evolution: the synergistic ape. Nature's magic: Synergy in evolution and the fate of humankind. Cambridge and New York: Cambridge University

Press.

Cowan, \& James, P. (1994). Handbook of environmental acoustics. New York: Van Nostrand Reinhold.

Das, D., \& Waychal, A. (2016). On the triboelectrically charged nonwoven electrets for air filtration. Journal of Electrostatics, 83, 73-77.

Davies, C. N. (1952). The separation of airborne dust and particles. Proceedings of the institution of mechanical engineers, 1B, 185-198.

Davies, C. N. (1973). Air filtration. London: Academic Press.

EPAH (1991). Building air quality guide: Ag guide for buildin owners and facility managers [Online]. Available: https:/ / www.epa.gov/indoor-air-quality-iaq/building-air- quality-guide-guide-building-owners-andfacility-managers [Accessed 8 December 2016].

Endo, Y., Chen, D., \& Pui, D. Y. H. (2002). Theoretical consideration of permeation resistance of fluid through a particle packed layer. Powder Technology, 124, 119-126.

European Commission (2010). European commission air quality standards [Online]. Available: http://ec.europa.eu/environment/air/quality/standards.htm [Accessed 15 May 2016].

Ezhilvalavan, S., Branicio, P. S., Kong, L. B., Sundarrajan, S., Tan, K. L., Lim, S. H., et al. (2014). International conference on materials for advanced technologies (ICMAT2013): Symposium W - advanced structural and functional materials for protection electrospun nanofibers for air filtration applications. Procedia Engineering, $75, \quad 159-163$.

Farhanian, D., \& Haghighat, F. (2014). Photocatalytic oxidation air cleaner: Identification and quantification of by-products. Building and Environment, 72, 34-43.

Farhanian, D., Haghighat, F., Lee, C.-S., \& Lakdawala, N. (2013). Impact of design parameters on the performance of ultraviolet photocatalytic oxidation air cleaner. Building and Environment, 66, 148-157.

Fisk, W. J., Faulkner, D., Palonen, J., \& Seppanen, O. (2002). Performance and costs of particle air filtration technologies. Indoor Air, 12, 223-234.

Friedlander, S. K. (1958). Theory of aerosol filtration. Industrial \& Engineering Chemistry, 50, 1161-1164.

Fu, H., Kang, Y., \& Shen, H. (2010). Collection efficiency of fibrous filter on dust load. 4th international conference on bioinformatics and biomedical engineering.

Gallagher, M. J., Vaze, N., Gangoli, S., Vasilets, V. N., Gutsol, A. F., \& Milovanova, T. N. (2007). Rapid inactivation of airborne bacteria using atmospheric pressure dielectric barrier grating discharge. IEEE Transactions on Plasma Science, 35, 1501-1510.

General Administration Of Quality Supervision, Administration Of The People's Republic Of China \& Inspection And Quarantine Of The People's Republic Of China And Standardization (2003). Chinese Code for design of heating ventilation and air conditioning. Ministry of Construction of the People's Republic of China.

Gunnar, D. N., Lea, F. H., \& Peder, W. (1997). Chemical and biological evaluation of building material emissions approaches for setting indoor air standards or guidelines for chemicals II. Indoor Air, 7, 17-32.

Hanley, J., Ensor, D., Smith, D., \& Sparks, L. (1994). Fractional aerosol filtration efficiency of induct ventilation air cleaners. Indoor Air, 4, 169-178.

Hartog, J. D. (2013). Conference room thermal comfort/HVAC architecture [Online]. Available: http://simhub.autodesk.com/projects/conference-room-thermal-comfort- hvac [Accessed 30 June 2016].

Huang, J., Mao, Q., Mei, H., \& Huang, B. (2001). Probe into mathematical model of pressure drop of the micropron membrane filter. Building Energy \& Environment, 1, 1-4.

Imbabi, M. S., \& Peacock, A. D. (2004). Allowing buildings to breathe. USA: Sovereign Publications.

Imbabi, M. S. E. (2006). Modular breathing panels for energy efficient: Healthy building construction. Renewable Energy, 31, 729-738.

Jamriska, M., Martin, D., \& Morawska, L. (1997). Investigation of the filtration efficiency of HEPA and ULPA filters in submicron particle size range. Clean Air Environment, 31, 31-37.

Japanese Government (2009). Environmental quality standards in Japan: Air quality [Online]. Ministry of the Environment Available: http://www.env.go.jp/en/air/aq/aq.html [Accessed 15 May, 2016].

Jasper, W., Hinestroza, J., Mohan, A., Kim, J., Shiels, B., Gunay, M., et al. (2006). Effect of xylene exposure on 
the performance of electret filter media. Journal of Aerosol Science, 37, 903-911.

Ji, J. H., Bae, G. N., Kang, S. H., \& Hwang, J. (2003). Effect of particle loading on the collection performance of an electret cabin air filter for submicron aerosols. Journal of Aerosol Science, 34, 1493-1504.

John, W., \& Reischl, G. (1978). Measurements of the filtration efficiencies of selected

filter types. Atmospheric Environment, 12, 2015-2019.

Joseph, S. D., Marc, A. D., \& Todd, S. W. (1999). Biofiltration for air pollution control.

Lewis: CRC Press.

Kanaoka, C., Emi, H., \& Myojo, T. (1980). Simulation of the growing Process of a Particle dendrite and evaluation of a single fiber collection efficiency with dust load. Journal of Aerosol Science, 11, 377-389.

Kanaoka, C., Emi, H., \& Tanthapanichakoon, W. (1983). Conventive diffusional deposition and collection efficiency of aerosol on a dust-loaded fiber. American Institute of Chemical Engineers Journal, 29, 895-902.

Kapustina, E. A., \& Volodina, E. V. (2003). Air decontamination and the fine filtration system Potok 150MK. Aerospace and Environmental Medicine, 38, 57-58.

Khazraei Vizhemehr, A., Haghighat, F., Lee, C. S., \& Kholafaei, H. (2015). Evaluation of gas-phase filter performance for a gas mixture. Clean-Soil Air Water, 43, 469-478.

Kvetoslav, R. S. (1998). The history of dust and aerosol filtration. In K. R. Spurny (Ed.), Advance in aerosol filtration. Lewis: CRC Press.

Lee, T. G., Biasio, D. D., \& Santini, A. (1996). Health and the built environment: Indoor air quality. The University of Calgary.

Li, W., Shen, S. \& Li, H. (2016). Study and optimization of the filtration performance of multi-fiber filter.

Advanced Powder Téchnology, 27, 638-645.

Liang, Y., Wu, Y., Sun, K., Chen, Q., Shen, F., \& Zhang, J. (2012). Rapid inactivation of biological species in the air using atmospheric pressure nonthermal plasma.

Environmental Science \& Technology, 46, 3360-3368.

Lin, W. Y., Chang, Y. Y., Lien, C. T., \& Kuo, C. W. (2011). Separation characteristics of submicron particles in an electrostatic precipitator with alternating electric field Corona charger. Aerosol Science and Technology, 45, 393-400.

Liu, L., \& Wang, S. (2000). The development and applications of air Filter.

Filter \& Separator, 10, 8-9.

Liu, X. Y., Mason, M., Krebs, K., \& Sparks, L. (2004). Full-scale chamber investigation and simulation of air freshener emissions in the presence of ozone. Environmental Science E Technology, 38, 2802-2812.

Liu, B., Zhang, S., Wang, X., Yu, J., \& Ding, B. (2015). Efficient and reusable polyamide-56 nanofiber/nets membrane with bimodal structures for air filtration. Journal of Colloid and Interface Science, 457, 203-211.

Lu, Y., Wang, D., \& Sheng, J. (2009). The removal of formaldehyde by NTP combined with photocatalysis. Journal of Beijing University of Technology, 35, 664-667.

Ministry Of Environmental Protection Of China (2012). Ambient air quality standards.

Beijing: China Environmental Science.

Mallany, J., Darlington, A., \& Dixon, M. (2000). The biofiltration of indoor air II: Microbial loading of the indoor space. The 2000 USC-TRG conference on biofiltration and air pollution control (pp. 263-268). .

Matela, D. (2006). Air filtration: green and clean - how to improve indoor air quality. Filtration $\mathcal{E}$ Separation, 43, 24-27.

Maus, R., Goppelsröder, A., \& Umhauer, H. (2001). Survival of bacterial and mold spores in air filter media. Atmospheric Environment, 35, 105-113.

Mo, D., \& Ye, D. (2009). Surface study of composite photocatalyst based on plasma modified activated carbon fibers with TiO2. Surface and Coatings Technology, 203, 1154-1160.

Montazer, M., \& Malekzadeh, S. B. (2012). Electrospun antibacterial nylon nanofibers through In situ synthesis of nanosilver: Preparation and characteristics. Journal of Polymer Research, 19, 9980.

Montgomery, J. F., Green, S. I., Rogak, S. N., \& Bartlett, K. (2012). Predicting the energy use and operation cost of HVAC air filters. Energy and Buildings, 47, 643-650.

Myers, D. L., \& Arnold, B. D. (2003). Mechano-electret filtration media: Synergy of structure and electrostatic charge. Filtration \& Separation, 40, 24-27.

Nazaroff, W. W., \& Weschler, C. J. (2004). Cleaning products and air fresheners: Exposure to primary and secondary air pollutants. Atmospheric Environment, 38, 2841-2865.

Novick, V. J., Monson, P. R., \& Ellison, P. E. (1992). The effect of solid particle mass loading on the pressure drop of HEPA filters. Journal of Aerosol Science, 23, 657-665. 
Othman, A. R., \& Sahidin, N. (2016). Vertical greening façade as passive approach in sustainable design. Procedia - Social and Behavioral Sciences, 222, 845-854.

Pérez-Urrestarazu, L., Fernández-Cañero, R., Franco, A., \& Egea, G. (2016). Influence of an active living wall on indoor temperature and humidity conditions. Ecological Engineering, 90, 120-124.

Park, C. W., Byeon, J. H., Yoon, K. Y., Park, J. H., \& Hwang, J. (2011). Simultaneous removal of odors, airborne particles, and bioaerosols in a municipal composting facility by dielectric barrier discharge. Separation and Purification Technology, 77, 87-93.

Passchier-Vermeer, W., \& Passchier, W. F. (2000). Noise exposure and public health. Environmental Health Perspectives, 108, 123-131.

Payet, S., Boulaud, D., Madelaine, G., \& Renoux, A. (1992). Penetration and pressure drop of a HEPA filter during loading with submicron liquid particles. Journal of Aerosol Science, 23, 723-735.

Paz, Y. (2010). Application of TiO2 photocatalysis for air treatment: Patents' overview. Applied Catalysis B: Environmental, 99, 448-460.

Podgórski, A., Bałazy, A., \& Gradoń, L. (2006). Application of nanofibers to improve the filtration efficiency of the most penetrating aerosol particles in fibrous filters. Chemical Engineering Science, 61, 6804-6815.

Price, D. L., Simmons, R. B., Crow, S. A. J., \& Ahearn, D. G. (2005). Mold colonization during use of preservative-treated and untreated air filters, including HEPA filters from hospitals and commercial locations over an 8-year period (1996-2003). Journal of Industrial Microbiology and Biotechnology, 32, 319321.

Rosner, D. E., Tandon, P., \& Konstanpulous, A. G. (1995). Local size distribution of particles deposited by internal impaction on cylindrical target in dust-load. Aerosol Science, 26, 1257-1279.

Sae-Lim, W., Tanthapanichakoon, W., \& Kanaoka, C. (2004). Collection efficiency enhancement factor of an electret fiber under dust load. Regional symposium on chemical engineering.

Salthammer, T. (2004). Emissions of volatile organic compounds from products and materials in indoor environments. In P. Pluschke (Ed.), The handbook of environmental chemistry. Berlin, Heidelberg: SpringerVerlag.

Sarwar, G., Olson, D. A., Corsi, R. L., \& Weschler, C. J. (2004). Indoor fine particles: The role of terpene emissions from consumer products. Journal of the Air \& Waste Management Association, 54, 367-377.

Schroth, T. (1996). New HEPA/ ULPA filters for clean-room technology. Filtration \& Separation, 33, 245-250.

Setekleiv, A., Eddie, S., \& Hallvard, F. (2012). Operation and dynamic behavior of wire mesh pads. Chemical Engineering Journal, 68, 624-639.

Shenghsiu, H., Chunwan, C., Yumei, K., Chaneyu, L., Roy, M., \& Chihchieh, C. (2013). Factors affecting filter penetration and quality factor of particulate respirators.

Aerosol and Air Quality Research, 13, 162-171.

Sim, K. M., Park, H.-S., Bae, G.-N., \& Jung, J. H. (2015). Antimicrobial nanoparticle- coated electrostatic air filter with high filtration efficiency and low pressure drop. Science of The Total Environment, 533, $266-274$.

Singer, B. C., Coleman, B. K. Deștaillats, H., Hodgson, A. T., Lunden, M. M., Weschler, C. J., et al. (2006). Indoor secondary pollutants from cleaning product and air freshener use in the presence of ozone. Atmospheric Environment, 40, 6696-6710.

Soreanu, G., Dixon, M., \& Darlington, A. (2013). Botanical biofiltration of indoor gaseous pollutants-A minireview. Chemical Engineering Journal, 229, 585-594.

Subrahmanyam, C., Magureanu, M., Renken, A., \& Kiwi-Minsker, L. (2006). Catalytic abatement of volatile organic compounds assisted by non-thermal plasma: Part 1. A novel dielectric barrier discharge reactor containing catalytic electrode. Applied Catalysis B: Environmental, 65, 150-156.

Tanthapanichakoon, W., Maneeintr, K., Charinpanitkul, W., \& Kanaoka, C. (2003). Estimation of collection efficiency enhancement factor for an electret fiber with dust load. Journal of Aerosol Science, 34, 1505-1522.

Thomas, D., Penicot, P., Contal, P., Leclerc, D., \& Vendel, J. (2001). Clogging of fibrous filters by solid aerosol particles Experimental and modelling study. Chemical Engineering Science, 56, 3549-3561.

Tronville, P. (2009). Air filtration and efficiency: Air filters - energy rating and labelling. Filtration \& Separation, 46, 26-29.

Tsai, P. P., \& Ke, Q. (2003). Worldwide technology trend in filter media. Technical Textiles, 21, 8-11.

United States Environmental Protection Agency (2006). National ambient air quality standards (NAAQS) [Online]. US. Available: https://www.epa.gov/criteria-air-pollutants/naaqs-table [Accessed 15 May 2016]. 
Van Durme, J., Dewulf, J., Sysmans, W., Leys, C., \& Van Langenhove, H. (2007). Efficient toluene abatement in indoor air by a plasma catalytic hybrid system. Applied Catalysis B: Environmental, 74, 161-169.

WHO (2006). WHO Air quality guidelines for particulate matter, ozone, nitrogen dioxide and sulphur dioxide [Online]. Available: http:/ / apps.who.int/iris/bitstream/10665/ 69477/1/WHO_SDE_PHE_OEH_06.02_eng.pdf?ua=1 [Accessed 30 April 2016].

Walsh, D. C., \& Stenhouse, J. I. T. (1997). The effect of particle size, charge, and composition on the loading characteristics of an electrically active fibrous filter material. Journal of Aerosol Science, 28, 307-321.

Wang, Z., \& Pan, Z. (2015). Preparation of hierarchical structured nano-sized/porous poly (lactic acid) composite fibrous membranes for air filtration. Applied Surface Science, 356, 1168-1179.

Wang, Z., \& Zhang, J. S. (2011). Characterization and performance evaluation of a full- scale activated carbon-based dynamic botanical air filtration system for improving indoor air quality. Building and Environment, 46, 758-768.

Wang, J., Kim, S. C., \& Pui, D. Y. H. (2008). Investigation of the figure of merit for filters with a single nanofiber layer on a substrate. Journal of Aerosol Science, 39, 323-334.

Wang, N., Raza, A., Si, Y., Yu, J., Sun, G., \& Ding, B. (2013). Tortuously structured polyvinyl chloride/ polyurethane fibrous membranes for high-efficiency fine particulate filtration. Journal of Colloid and Interface Science, 398, 240-246.

Wang, H., Yang, Z. Y., Liu, J. Y., Zheng, G. F., \& Liu, Y. P. (2016). Research on the advantages of nanofibrous air filtration membrane. Key Engineering Materials, 474-476, 2016-2019. 
Wang, C. S. (2001). Electrostatic forces in fibrous filters-a review. Powder Technology, 118, 166-170.

Wen, T. Y., Wang, H. C., Krichtafovitch, I., \& Mamishev, A. V. (2015). Novel electrodes of an electrostatic precipitator for air filtration. Journal of Electrostatics, 73, 117-124.

Wolkoff, P., \& Kjærgaard, S. K. (2007). The dichotomy of relative humidity on indoor air quality. Environment International, 33, 850-857.

Wolkoff, P., Schneider, T., Kildesø, J., Degerth, R., Jaroszewski, M., \& Schunk, H. (1998). Risk in cleaning: Chemical and physical exposure. Science of The Total Environment, 215, 135-156.

Wood, A., Bahrami, P., \& Safarik, D. (2014). Green walls in high-rise buildings: An output of the CTBUH sustainability working group. The Images Publishing Group.

Xiaoyu, N., Hong, C., \& Jing, G. (2009). Advances inresearches on catalysis-assisted non- thermal plasma technologyfor air pollution control. Science \& Technology Review, 27, 97-100.

Xu, Y., Zheng, C., Liu, Z., \& Yan, K. (2013). Electrostatic precipitation of airborne bio-aerosols. Journal of Electrostatics, 71, 204-207.

Yang, Y., Zhang, S., Zhao, X., Yu, J., \& Ding, B. (2015). Sandwich structured polyamide-6/ polyacrylonitrile nanonets/bead-on-string composite membrane for effective air filtration. Separation and Purification Technology, 152, 14-22.

Yoneyama, H., \& Torimoto, T. (2000). Titanium dioxide/adsorbent hybrid photocatalysts for photodestruction of organic substances of dilute concentrations. Catalysis Today, 58, 133-140.

Zaatari, M., Novoselac, A., \& Siegel, J. (2014). The relationship between filter pressure drop, indoor air quality, and energy consumption in rooftop HVAC units. Building and Environment, 73, 151-161.

Zhang, X., Li, H., Zhao, M., Wu, M., Fang, D., \& Ma, H. (2015). Compound antibiotic filtration filter core, screen window, air purification device and gauze mask. Shanghai: Shanghai Jie Sheng Environmental Protection Technology Co., LTD.

Zhang, L., Luo, J., Menkhaus, T. J., Varadaraju, H., Sun, Y., \& Fong, H. (2011). Antimicrobial nano-fibrous membranes developed from electrospun polyacrylonitrile nanofibers. Journal of Membrane Science, 369, 499-505.

Zhang, Y., Mo, J., Li, Y., Sundell, J., Wargocki, P., Zhang, J., et al. (2011). Can commonly- used fan-driven air cleaning technologies improve indoor air quality? A literature review. Atmospheric Environment, 45, 4329-4343.

Zhong, L., \& Haghighat, F. (2015a). Competitive adsorption behaviour of binary mixtures on titanium dioxide. The Canadian Journal of Chemical Engineering, 93, 1657-1666.

Zhong, L., \& Haghighat, F. (2015b). Photocatalytic air cleaners and materials technologies-Abilities and limitations. Building and Environment, 91, 191-203.

Zhong, L., Haghighat, F., Lee, C.-S., \& Lakdawala, N. (2013). Performance of ultraviolet photocatalytic oxidation for indoor air applications: systematic experimental evaluation. Journal of Hazardous Materials, 261, 130138.

Zhu, J., Zhao, Q., Yao, Y., Luo, S., Guo, X., Zhang, X., et al. (2012). Effects of high-voltage power sources on fine particle collection efficiency with an industrial electrostatic precipitator. Journal of Electrostatics, 70, 285291. 
